$9-1-2020$

\title{
Piloting and evaluating family-centered HIV care in Eswatini
}

\author{
Caspian Chouraya \\ Nobuble Mthethwa \\ Lynne Mofenson \\ Philisiwe Khumalo \\ Lydia Mpango
}

See next page for additional authors

Follow this and additional works at: https://knowledgecommons.popcouncil.org/departments_sbsr-hiv

Part of the Public Health Commons

How does access to this work benefit you? Let us know!

\section{Recommended Citation}

Chouraya, Caspian, Nobuble Mthethwa, Lynne Mofenson, Philisiwe Khumalo, Lydia Mpango, Munamato Mirira, Rhoderick Machekano, Leila Katirayi, and Kim Ashburn. 2020. "Piloting and evaluating familycentered HIV care in Eswatini," Project SOAR Final Report. Washington, DC: Population Council. 


\section{Authors}

Caspian Chouraya, Nobuble Mthethwa, Lynne Mofenson, Philisiwe Khumalo, Lydia Mpango, Munamato Mirira, Rhoderick Machekano, Leila Katirayi, and Kim Ashburn 


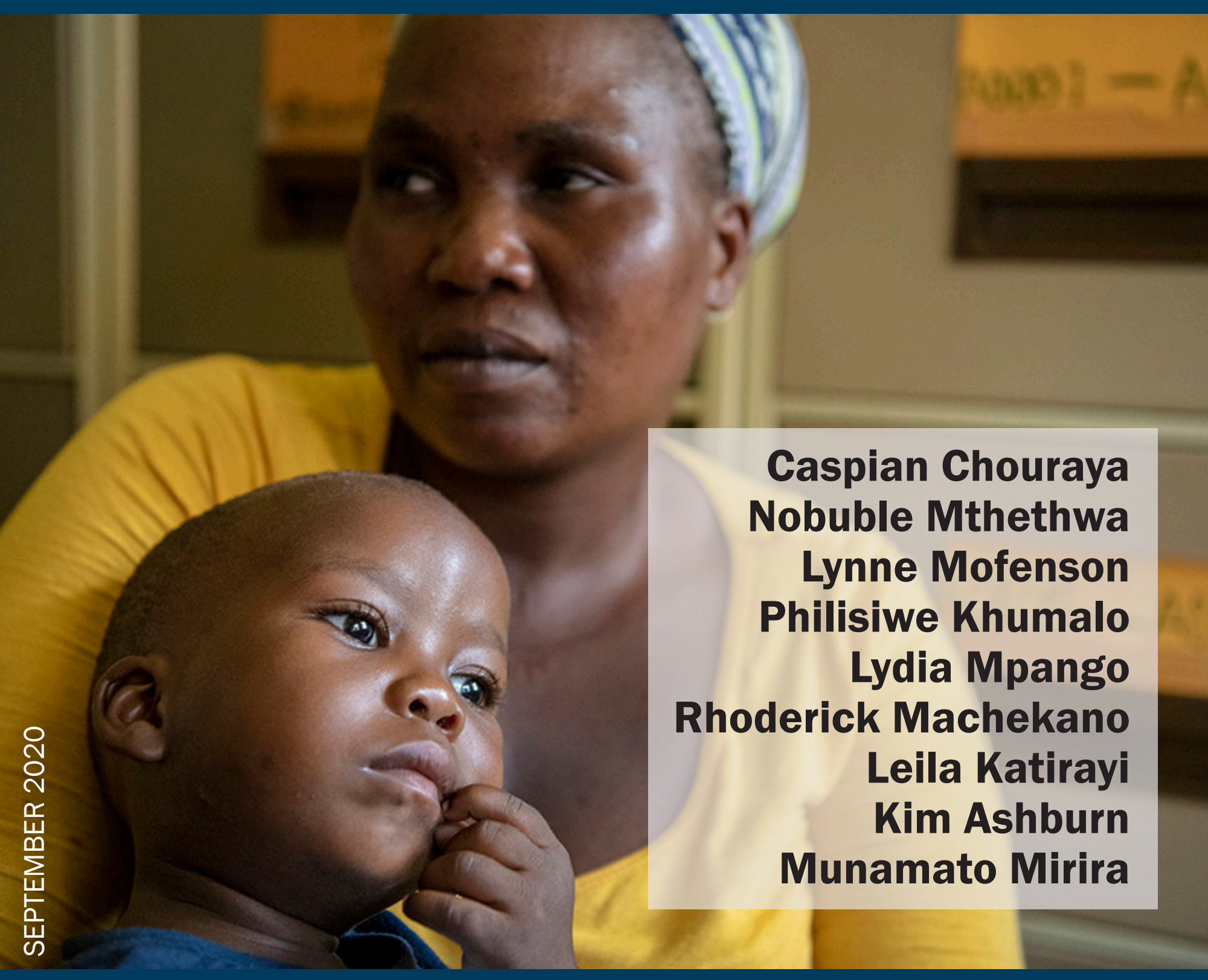

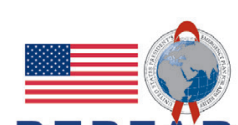
PEPFÁR

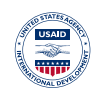

USAID

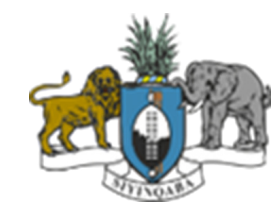




\section{Project SOAR}

Population Council

4301 Connecticut Ave, NW, Suite 280

Washington, D.C. 20008 USA

Tel: +12022379400

Fax: +1 2022378410

\section{projsoar.org}
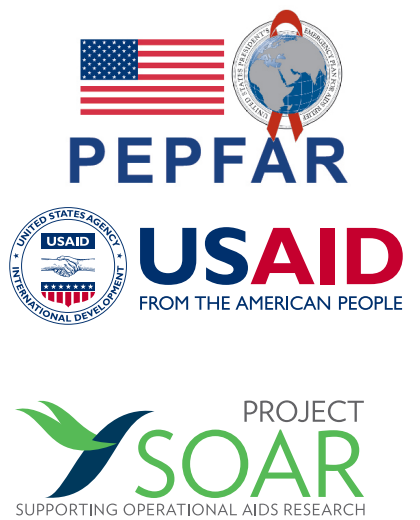

\section{- POPULATION COUNCIL}

Ideas. Evidence. Impact.
Project SOAR (Cooperative Agreement AID-OAA-A-14-00060) is made possible by the generous support of the American people through the United States President's Emergency Plan for AIDS Relief and the United States Agency for International Development (USAID). The contents of this report are the sole responsibility of Project SOAR and the Population Council and do not necessarily reflect the views of PEPFAR, USAID, or the United States Government.

Through operations research, Project SOAR will determine how best to address challenges and gaps that remain in the delivery of HIV and AIDS care and support, treatment, and prevention services. Project SOAR will produce a large, multifaceted body of high-quality evidence to guide the planning and implementation of HIV and AIDS programs and policies. Led by the Population Council, Project SOAR is implemented in collaboration with Avenir Health, Elizabeth Glaser Pediatric AIDS Foundation, Johns Hopkins University, Palladium, and The University of North Carolina.

The Population Council confronts critical health and development issues-from stopping the spread of HIV to improving reproductive health and ensuring that young people lead full and productive lives. Through biomedical, social science and public health research in about 50 countries, the Council works with our partners to deliver solutions that lead to more effective policies, programs, and technologies to improve lives worldwide. Established in 1952 and headquartered in New York, the Council is a nongovernmental, nonprofit organization with an international board of trustees.

\section{Elizabeth Glaser Pediatric AIDS Foundation}

The Elizabeth Glaser Pediatric AIDS Foundation (EGPAF) is a nonprofit organization that seeks to end HIV/AIDS globally in children, youth, and families. Founded in 1988, EGPAF supports activities in 19 countries worldwide. In collaboration with local partners, EGPAF advances research and innovation, advocates for global and local policies and resources, optimizes integrated service delivery programs, and builds global, national, and local capacity through tailored technical assistance to sustain a high-quality, locally-owned response to end the HIV/AIDS epidemic.

Cover photo credit: Elizabeth Glaser Pediatric AIDS Foundation

Published in September 2020. (C2020 The Population Council, Inc.

Suggested citation: Chouraya, Caspian, Nobuble Mthethwa, Lynne Mofenson, Philisiwe Khumalo, Lydia Mpango, Munamato Mirira, Rhoderick Machekano, Leila Katirayi, Kim Ashburn. 2020. "Piloting and evaluating family-centered care in Eswatini," Project SOAR Final Report. Washington, D.C.: Population Council. 


\section{Piloting and Evaluating Family-centered HIV Care in Eswatini}

Caspian Chouraya ${ }^{1}$, Nobuble Mthethwa ${ }^{2}$, Lynne Mofenson ${ }^{3}$, Philisiwe Khumalo ${ }^{1}$, Lydia Mpango ${ }^{1}$, Rhoderick Machekano ${ }^{3}$, Leila Katirayi ${ }^{3}$, Kim Ashburn $^{3}$, Munamato Mirira ${ }^{4}$

${ }^{1}$ Elizabeth Glaser Pediatric AIDS Foundation (EGPAF), Eswatini

${ }^{2}$ Eswatini Ministry of Health

${ }^{3}$ EGPAF, USA

${ }^{4}$ USAID/Eswatini
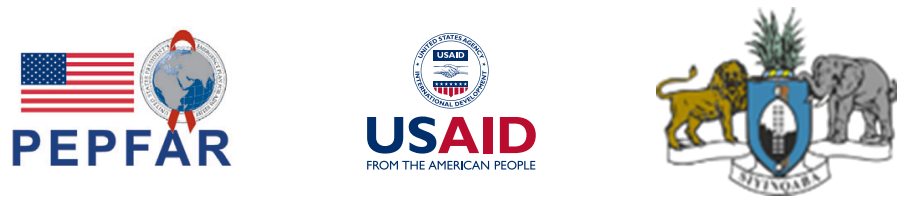


\section{ACKNOWLEDGMENTS}

This study was conducted by the Elizabeth Glaser Pediatric AIDS Foundation in collaboration with the Eswatini Ministry of Health. The authors would like to acknowledge the Ministry of Health in partnering with us in this unique opportunity to test a family-centered approach for improving HIV outcomes for children in Eswatini. We would also like to thank the hard work and dedication of the study team and data collectors, including Bhekisisa Tsabedze, Sandile Mchunu, Nonqaba Keatimilwe, Sicelo Vilane, Nothando Dlamini, Tekugcina Khumalo, Thabo Dlamini, Nkosilathi Jamela, Dumsile Simelane, Zethu Msibi, Nondumiso Lukhele, Zwakele Dlamini, Zazi Zikalala, and Bhekisisa Masilela during the FAM-CARE study. Finally, we want to express our gratitude to the families who participated in the FAM-CARE pilot program evaluation. Without their participation, this study would not have been possible. This work would not have been possible without the active support of the United States Agency for International Development mission team in Eswatini. We acknowledge our USAID colleagues who dedicated time and effort to this project. 


\section{TABLE OF CONTENTS}

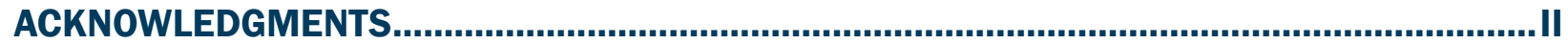

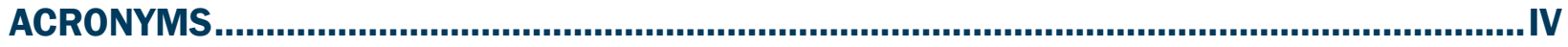

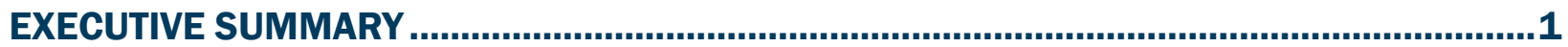

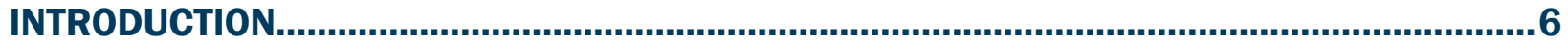

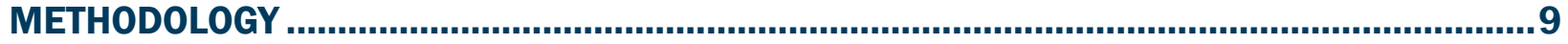

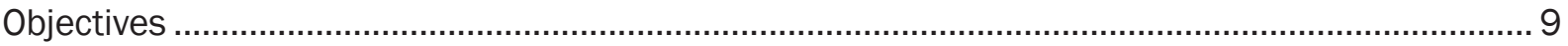

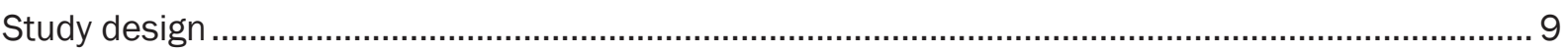

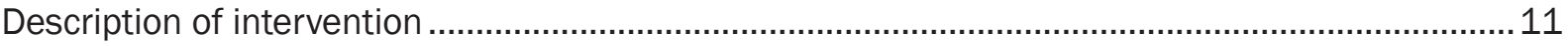

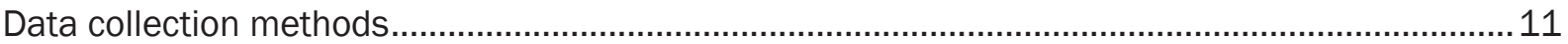

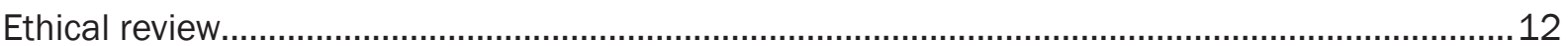

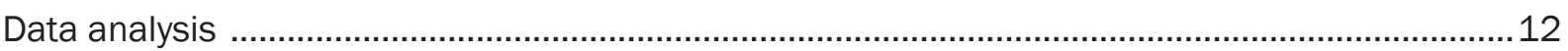

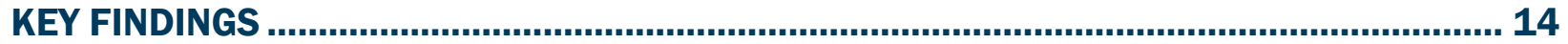

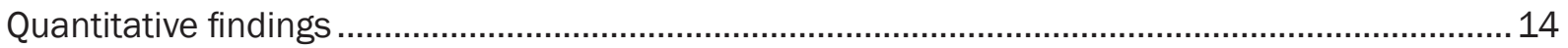

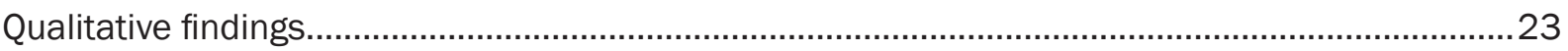

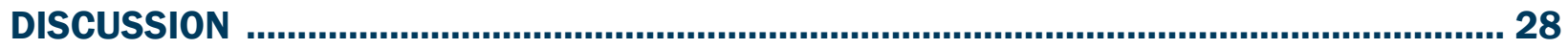

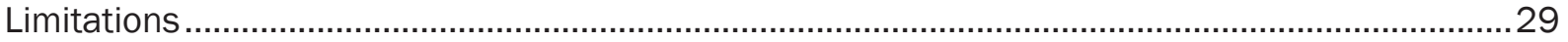

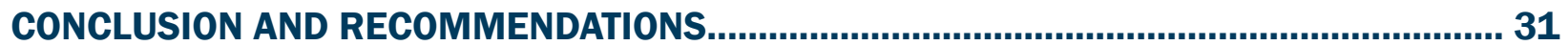

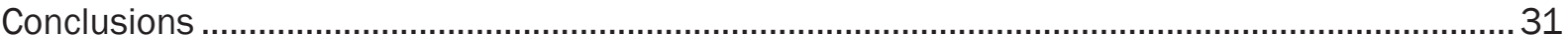

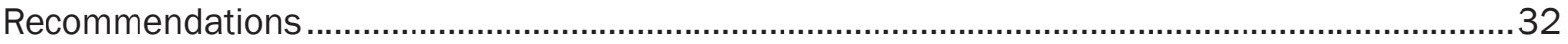

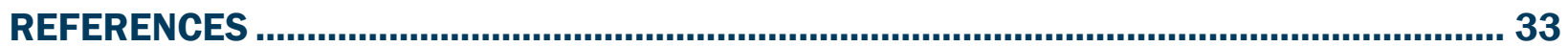

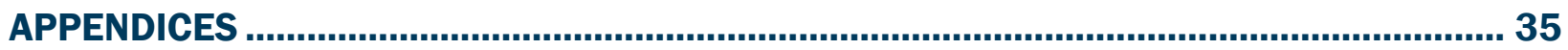

Appendix 1: Schema of study design for the evaluation of FAM-CARE Program design ..................35

Appendix 2: Data collection activities .....................................................................................36

Appendix 3: IDIs conducted in each FAM-CARE program site .....................................................36

Appendix 4: Five steps in providing FCCM from FCCM standard operating procedures (SOP).........37

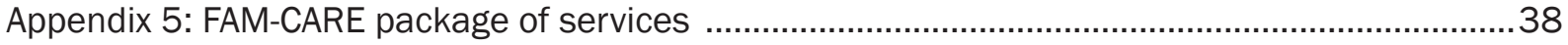

Appendix 6: EGPAF Evidence to action: Urgent update! Optimizing pediatric regimens brief ..........39

Appendix 7: A map of Eswatini FAM-CARE study sites and catchment area .................................45 


\section{ACRONYMS}

$\begin{array}{ll}\text { 3TC } & \text { Lamivudine } \\ \text { ABC } & \text { Abacavir } \\ \text { ART } & \text { Antiretroviral therapy } \\ \text { ARV } & \text { Antiretroviral drugs } \\ \text { AZT } & \text { Zidovudine } \\ \text { CTX } & \text { Cotrimoxazole } \\ \text { DBS } & \text { Dried blood spot } \\ \text { DSD } & \text { Differentiated service delivery model } \\ \text { EFV } & \text { Efavirenz } \\ \text { FAM-CARE } & \text { Family-centered care model study } \\ \text { FCCM } & \text { Family-centered care model program } \\ \text { HW } & \text { Health worker } \\ \text { HTS } & \text { HIV testing services } \\ \text { IDI } & \text { In-depth interview } \\ \text { IPT } & \text { Isoniazid preventive therapy } \\ \text { LPV/r } & \text { Lopinavir/ritonavir } \\ \text { NVP } & \text { Nevirapine } \\ \text { PEPFAR } & \text { United States President's Emergency Plan for AIDS Relief } \\ \text { PMTCT } & \text { Prevention of mother-to-child transmission } \\ \text { SOP } & \text { Standard operating procedures } \\ \text { TDF } & \text { Tenofovir disoproxil fumarate } \\ \text { UNAIDS } & \text { Joint United Nations Programme for HIV/AIDS } \\ \text { USAID } & \text { United States Agency for International Development } \\ \text { WHO } & \text { World Health Organization } \\ & \\ \text { HT } & \end{array}$




\section{EXECUTIVE SUMMARY}

While there has been remarkable global progress in the prevention of mother-to-child HIV transmission (PMTCT), efforts to scale up antiretroviral therapy (ART) and achieve the Joint United Nations Programme on HIV/AIDS (UNAIDS) "90-90-90" targets (90\% diagnosed, 90\% of those infected on ART, $90 \%$ on ART viral suppressed) have been less robust in children than in adults living with HIV. These discrepancies reflect substantial gaps in essential services and numerous missed opportunities to engage children in care and provide effective treatment. Although not new, family-centered care models that provide HIV services comprehensively to families as a unit, rather than providing separate services to children and adults, have the potential to address family needs and break down social, physical, and emotional barriers to accessing care. The family-centered care study (FAM-CARE) aims to contribute to our understanding of the role of family-centered care models (FCCM) in improving pediatric HIV outcomes in a sub-Saharan African setting.

\section{Methodology}

The FCCM program is a model where a child or adolescent $(0-<19$ years old) living with HIV is provided HIV care and treatment services with at least one family member involved in the support for the child. Family members include children and adults, HIV-negative and HIV-positive. For family members who have unknown HIV status, HIV counseling and testing and follow up services are provided. Participants attend clinic visits together as a family unit to receive HIV care, including laboratory and pharmacy services. Participants see the same provider at each visit, medications for family members could be collected by one family member, and a comprehensive filing system allowed all clinical records for each family to be stored in one folder. Clinic visits are scheduled for a minimum of four visits per year; all medical records are to be pulled for all family members ahead of the visit and FCCM participants prioritized in receiving services at the facility.

The FAM-CARE study enrolled a prospective cohort of children living with HIV (age <15 years) and their caregivers (HIV-positive or HIV-negative) and other family members living with HIV to evaluate the effects of a FCCM. Four facility clusters (two hospitals and two health facilities, and their filter clinics) in the Hhohho region of Eswatini were randomized to either implement the FCCM intervention, where all family members living with HIV are seen together as a unit and receive their care together, or to the control standard of care group, where adults and children are seen in separate clinics. The cohort of 379 children living with HIV was followed in both arms for a minimum of 12 months after enrollment. The primary objective was to evaluate the effect of the FCCM program on the rates of viral suppression and retention in care, comparing children enrolled in FCCM versus control sites. The study also evaluated factors associated with viral suppression and retention. Caregiver interviews and medical chart abstraction were used to collect data on demographic characteristics, HIV and ART history, interim HIV history, viral load, CD4 count, medical visit attendance, and drug pick-ups for children living with HIV and any caregivers or family members living with HIV. For children, viral load was obtained as part of the study at enrollment, 6 , and 12 months (and 18 months for those followed through that 
time), with laboratory assays conducted at a central laboratory. Qualitative in-depth interviews with caregivers and health workers at the intervention sites were used to assess feasibility and acceptability of the FCCM model.

\section{KEY FINDINGS}

\section{Quantitative findings}

A cohort of 379 children living with HIV and their caregivers from 363 unique families, including 363 caregivers ( $97 \%$ living with HIV themselves) and 28 other family members living with HIV (children, adolescents, and adults), were enrolled and followed for a minimum of 12 months; 87 percent had follow-up through 12 months and 57 percent through 18 months. Other family members included children, adolescents, and adults living with HIV, living in the same household as the child living with HIV enrolled in the FAM-CARE study.

\section{Treatment regimen at enrollment}

At enrollment, 43 percent of children were receiving nevirapine-based ART regimens. These nevirapine-based regimens are considered suboptimal and were associated with lower levels of viral suppression. These findings directed attention to the critical need to review pediatric treatment regimens and optimize ART regimens for all children as they grow and as more potent and less toxic regimens become available. These findings were published in 2019 in the Pediatric Infectious Diseases Journal.

\section{Viral suppression and undetectable viremia}

Viral suppression (HIV RNA $<1,000$ copies/mL) improved in both study arms from 78 percent at enrollment to 90 percent at 12 months and 87 percent for those followed to 18 months. Children with undetectable viral load (HIV RNA $<400$ copies $/ \mathrm{mL}$ ) improved from 74 percent at enrollment to 87 percent at 12 months and 84 percent for those followed to 18 months. Overall, among children who had viral suppression at enrollment, 97 percent remained suppressed at 12 months follow up; 62 percent of children who were unsuppressed at enrollment achieved viral suppression at 12 months follow up. There were no statistically significant differences in the intervention versus control groups in viral suppression or undetectable viral load at 12 or 18 months follow-up.

\section{Factors associated with viral suppression and undetectable viremia}

In unadjusted bivariate analyses among all children at 12 months after enrollment, several factors were associated with viral suppression (HIV RNA $<1,000$ copies $/ \mathrm{mL}$ ). Children who were not aware of their HIV status tended to be less likely than children who were aware of their HIV status to be virally suppressed (OR:0.46; 95\% Cl:0.20, 1.08, p=0.068). Compared to children with caregivers under age 25 years, children with older caregivers aged 30-40 years (OR: 5.53; 95\% $\mathrm{Cl}: 1.80,17.00)$ and aged $>40$ years (OR: 3.93; 95\% Cl:1.30, 11.85) were significantly more likely to be suppressed. The odds of suppression among children with HIV-negative caregivers were 
significantly lower than the odds of suppression among children with HIV-positive caregivers (OR: 0.15; 95\% Cl: 0.05, 0.49). At study entry, children on nevirapine (NVP)-based ART had significantly lower levels of viral suppression (73\%) than those on efavirenz (EFV) (87\%) or lopinavir-ritonavir $(\mathrm{LPV} / \mathrm{r})$-based (79\%) ART ( $\mathrm{p}=0.042)$. At 12 months, while rates of viral suppression remained lowest in those on NVP-based ART (87\%) compared to EFV-based (94\%) and LPV/r-based (91\%) ART, this was not statistically significant $(p=0.31)$. Study intervention versus control group was not significantly associated with viral suppression at $12(p=0.48)$ or 18 months $(p=0.08)$ after enrollment.

In unadjusted bivariate analyses among all children at 12 months after enrollment, similar factors were associated with undetectable viremia (HIV RNA $<400$ copies $/ \mathrm{mL}$ ). The odds of undetectable viremia tended to be lower among children who did not know their HIV status compared to children who knew their HIV status (OR: $0.55 ; 95 \% \mathrm{Cl}: 0.26,1.14, \mathrm{p}=0.10$ ). Children in the care of caregivers aged $30-40$ years (OR: $5.24 ; 95 \% \mathrm{Cl}: 1,83,15.04$ ) and aged $>40$ years (OR:3.15; $95 \% \mathrm{Cl}: 1.14,8.68)$ were significantly more likely to have undetectable viremia than children with younger aged caregivers ( $<25$ years). Children in the care of HIV-negative caregivers versus caregivers living with HIV were less likely to have undetectable viremia (OR:0.15; 95\% $\mathrm{Cl}$ : 0.05, 0.46). Although rates of undetectable viremia at 12 months after enrollment were lowest in those on NVP-based ART (84\%) compared to EFV-based (90\%) and LPV/r-based (89\%) ART, this was not statistically significant ( $p=0.38$ ). Study intervention versus control group was not significantly associated with undetectable viremia at $12(p=0.63)$ or 18 months $(p=0.38)$ after enrollment.

There was a non-significant trend toward higher odds of viral suppression and undetectable viremia among older versus younger children. Overall, 94 percent of children aged 10-14 years had viral suppression at 12 months follow-up compared with 90 percent of children aged 5-9 years and 85 percent of children aged $<5$ years. Similarly, undetectable viral load was observed in 91 percent of children 10-14 years, 87 percent of those aged 5-9 years, and 81 percent of those aged $<5$ years. There was not a significant difference in the levels of suppression or detectability by intervention versus control groups when stratified by age.

\section{Retention, adherence, treatment interruption, and HIV disclosure}

There were no significant differences between intervention and control groups in retention in care, interruption of ART, reported adherence, or disclosure at 12 months (Table 5). At 12 months follow-up, 93 percent of children expected to be seen at the 12-month visit had a documented clinic visit, with no significant difference between groups (91\% intervention, 94\% control, $\mathrm{p}=0.53$ ). At the 12-month visit, ART interruption was reported by 16 percent in the intervention and 15 percent in the control groups ( $p=0.82)$; good adherence was reported by 84 percent in the intervention and 87 percent of the control groups $(p=0.32)$; and last two drug pick-ups were reported to be on time for 88 percent of intervention and 92 percent of control group children $(p=0.18)$. The proportion of children who did not know their HIV status at enrollment but learned of their HIV status during the study was low and not statistically different between groups (6\% intervention and $5 \%$ control, $p=0.69$ ). In the more limited sample of 216 children with 18-month follow-up, 12 percent reported ART interruption, 93 percent reported good ART adherence, and $87 \%$ percent reported the last two drug pick-ups were on time, with no significant differences between groups. 


\section{Qualitative findings}

\section{Benefits of FCCM}

Caregivers liked the FCCM model because they felt it encouraged family members to disclose their HIV status to other family members and support each other in taking antiretroviral (ARV) drug regimens. Caregivers reported that they thought FCCM encouraged men to take a proactive support role for both women and children in HIV care and treatment, and reduced HIV-related stigma within the family. Caregivers viewed the counseling as better in the FCCM program than it was in the standard of care.

Health workers said FCCM program allowed them to track family histories, identify family challenges to HIV care and treatment, and identify long lasting solutions to problems. Overall, health workers perceived improved ART adherence, retention, and health status of children in the FCCM program.

\section{Challenges in FCCM}

Caregivers felt they had to incur additional costs for clinic visits for multiple family members, as the FCCM program required the family to visit the clinic together. There were schedule conflicts with school-aged children attending school and conflicts for older children who also attended weekend teen-support groups, as FCCM required additional family visits.

Within some facilities, health workers said that not all families attended clinic visits together as a family unit. Some families rotated family members to pick up ARV drug refills for the whole family. Health workers also had challenges with managing a large group of family members at the same time and noted staff shortages. Both caregivers and health workers mentioned difficulty in discussing sensitive health information in the presence of other family members.

\section{CONCLUSION AND RECOMMENDATIONS}

High levels of viral suppression and ART adherence (90\% and $85 \%$ overall, respectively) as well as retention were observed in both arms of the FAM-CARE study, which made it difficult to detect differences between children in control and intervention arms. Younger caregivers were less likely to have a child with viral suppression, and viral suppression was lower among children aged $<5$ years compared to older children.

The standard of care in Eswatini during the study period included viral load monitoring every 12 months for stable children less than 10 years old and every 6 months for children aged 10 to 19 years, and availability of teen support groups. Both intervention and control sites were to receive routine viral load testing every six months (although this was not always followed in the control sites) and the availability of teen support groups. In the control sites, it is possible that the additional attention of being enrolled in a study, with the caregiver interviewed at each study visit, resulted in improved viral suppression in this group, which limited the ability to detect a difference between control and intervention group participants. 
The FCCM program was well-liked by both caregivers and health care workers overall. Both caregivers and health workers viewed FCCM as encouraging HIV disclosure among family members and supporting each other in ART adherence, although analysis of FAM-CARE study data did not find differences in new HIV status disclosures to children or in ART adherence between study groups. Challenges discussed by both caregivers and health workers included clinic visit scheduling conflicts with school and teen support groups, making it difficult to implement FCCM as planned, as well as difficulties in discussing sensitive health information in the presence of other family members.

These results reflect the significant challenges for families with school-aged children in attending clinic visits together as a family as FCCM intended. For older children, teen support groups may be sufficient for ensuring positive outcomes in viral suppression and undetectable viremia. A higher proportion of older children achieved viral suppression and undetectable viremia ( $94 \%$ and $91 \%$, respectively, for those aged 10-14 years) in both arms at 12 months after enrollment than the younger children ( $85 \%$ and $82 \%$ respectively, for those aged $<5$ years).

Factors associated with viral suppression highlight important areas for enhancement in pediatric HIV care. Additional support (e.g., for keeping appointments, retention, understanding the need to take medication as prescribed, adherece) for adolescent or young adult caregivers, HIV-negative caregivers, caregivers of children under age 5 years, and for all caregivers in disclosing the child's HIV status could improve pediatric HIV outcomes. 


\section{INTRODUCTION}

Over the past two decades there has been much progress in prevention of mother-to-child HIV transmission in efforts to scale up antiretroviral therapy (ART) and achieve the Joint United Nations Programme on HIV/AIDS (UNAIDS) "90-90-90" targets (90\% diagnosis, 90\% of those infected-on ART, 90\% on ART with viral suppression). Achievement toward these goals has been less robust for children compared with adults (WHO 2014; UNAIDS 2014). These discrepancies reflect substantial gaps in essential services and numerous missed opportunities to engage children in care and provide effective ART.

With the 2016 WHO recommendations for universal treatment of all individuals living with HIV regardless of clinical or immune status, parents and children living with HIV will require ART (WHO 2016). The family forms the basic source of care and support for children in sub-Saharan Africa, and children's health and well-being are dependent on the physical, emotional, and social health of their parents and caregivers; a major aim of ART is to keep the family unit alive and well, benefitting caregivers and parents and also improving the well-being of their children (Leeper et al. 2010). Most HIV services are delivered with a focus on individual care, with little or less attention to their family or social context. Provision of ART has generally been separated for adults and children because of different areas of expertise and because prior treatment guidelines were dependent on CD4 and WHO clinical stage for ART eligibility, and children and their parents may have qualified for treatment months or years apart. However, comprehensive pediatric HIV prevention, treatment, and support will likely not be achieved if the child is taken out of the context of the family. Family-centered care models (FCCM) have emerged as an approach to comprehensively care for the needs of all HIV-positive family members, particularly the mother and child (Ritcher et al. 2010). Approaches that engage the family as a whole may offer advantages in improving retention in care and adherence with ART over the long run, and breaking barriers related to male partner involvement and disclosure processes (Rochat et al. 2011; Beatancourt et al. 2010).

While these models are not new, there are limited data to provide insights on the role of FCCM on pediatric and adult HIV outcomes. A 7-year retrospective analysis of data following implementation of an integrated family-focused approach to pediatric HIV care in 10 health facilities and 10 community clinics in Uganda reported a 50-fold increase in family units registered in health care (from 70 to 3,653), a 43-fold increase in children actively enrolled in care (from 86 to 3,726) and a 23-fold increase in children receiving ART (from 86 to 2,015) (Luyirika et al. 2013). In a study that examined the association between co-enrollment of family members living with HIV into care and outcomes of women initiating ART for PMTCT in 12 HIV care and treatment programs in eight sub-Saharan African countries, the risk of loss to follow-up was significantly greater among women living with HIV who did not have a family member living with HIV co-enrolled in care compared to those with a family member enrolled (19\% vs 3-8\% after 36 months on ART, respectively) (Myer et al. 2014). These limited data suggest that a family-focused care approach may lead to improved retention, ART adherence, and viral suppression for both children and adults. However, implementation of such a program has also been found to have 
challenges, including issues of disclosure to partners and difficulties in engaging male partners (Towne-Gold et al. 2009; Hosegood et al. 2010).

Additionally, achieving the third "90" (90\% viral suppression) is particularly challenging in children as most programs do not include pediatric viral load monitoring as part of routine care. The use of 2010/2013 WHO immunologic criteria to define treatment failure results in significant misclassification: in a study in Western Kenya, 6 percent (2 of 34) of children classified as treatment failure actually had undetectable viral load, and 65 percent ( 45 of 69) of children thought to have treatment success had detectable viral load, supporting WHO recommendations for routine viral load monitoring (Dufort et al. 2016). The potential use of viral load monitoring as a tool to promote adherence has had some evaluation among adults, but not among children. A meta-analysis of eight studies in eight countries found a trend for re-suppression following viral load testing with targeted adherence support for adults living with HIV found to have detectable viremia (Bonner et al. 2013). Studies are critically needed to determine how to optimally implement and use virologic testing among children living with HIV (Roberts et al. 2016).

In a recent large cross-sectional survey in Malawi and a 2013 systematic review of viral suppression in adults living with HIV on ART, viral suppression to HIV RNA $<1,000$ copies/mL ranged from 62 to 71 percent (intention-to-treat analysis) (McMahon et al. 2013; Maman et al. 2016). Data on virologic outcomes for children on ART in sub-Saharan Africa are more limited. In a cross-sectional survey of viral suppression (HIV RNA $<80$ copies $/ \mathrm{mL}$ ) among children on firstline ART for $>6$ months in 10 nurse-led clinics in Lesotho, viral suppression was found in only 72 percent of 191 children; no predictors for viral outcome were identified (Puga et al. 2016). Similarly, in a study of 742 children living with HIV initiating first-line ART in South Africa between 2008 and 2011, only 62 percent achieved a viral load $<50$ copies/mL six months after ART initiation (Pillay et al. 2015). In a descriptive study using data from a pilot program in 2012-2013 of routine viral load monitoring in 12,063 individuals living with HIV (including 580 children < 10 years and 588 adolescents 10-19 years) in Shiselweni, Eswatini, 16 percent were found to have detectable viral load (HIV RNA $\geq 100$ copies $/ \mathrm{mL}$ ); children had a 2.6-fold and adolescents a 3.2fold increased odds of having a detectable viral load (29\% of children $<10$ years and $35 \%$ of adolescents 10-19 years had detectable viremia) and were less likely to re-suppress at re-testing after adherence counseling (Jobanputra et al. 2015). Thus, the available pediatric data suggest viral suppression below the level of assay quantification (HIV RNA $<50-400 \mathrm{copies} / \mathrm{mL}$ ) is observed in 62 to 78 percent of children after $>6-24$ months of ART. In a pooled analysis of data from 5,485 children living with HIV who initiated ART at seven South African treatment programs with viral load monitoring, the probability of having a single viral load measurement $>1,000$ copies/mL was 17 percent at one year (95\% Cl 15.8-18.1) and 32 percent (95\% Cl 30.2-34.1) at 3 years after starting ART; the frequency of ART failure (two viral load $>1,000$ copies $/ \mathrm{mL}$ ) was 19 percent by 36 months (Davies et al. 2011). There are many factors that contribute to poor overall virologic response to ART and problems with retention and ART adherence in children, many of which stem from the fact that children are dependent upon adults for administration of their medications and attendance at clinic appointments. A family-focused program of care may serve to improve both pediatric retention in care and viral suppression.

In 2017, EGPAF-Eswatini initiated a pilot family-centered service delivery program in selected health facilities in the Hhohho region to provide more efficient and effective services to promote 
better ART initiation and retention in care for adults and children. The roll-out of these services provided a platform for introducing and evaluating routine HIV viral load testing and monitoring in children. Two of four health care clinic clusters in the region were randomized to provide the new FCCM, allowing a comparison of pediatric retention and viral load suppression between FCCM program and control facilities in which care for adults and children are provided separately. Data for the family care (FAM-CARE) study were collected during September 2017 and July 2019. 


\section{METHODOLOGY}

\section{OBJECTIVES}

The overall aim of this study was to demonstrate whether a family-centered care approach to HIV care through FCCM improved rates of viral suppression and retention of children living with HIV in care. The specific objectives of the FAM-CARE study were:

\section{Primary objectives}

1. Evaluate the effect of the FCCM program of HIV care on the proportion of children living with HIV on ART with viral suppression (defined as HIV RNA copies/mL below the level of assay detection) 18 months after enrollment.

2. Evaluate the effect of a FAM-CARE program of HIV care on the proportion of children living with HIV on ART with HIV RNA $\geq 1,000$ copies/mL 18 months after enrollment into the study.

\section{Secondary objectives}

1. Evaluate the effect of a FAM-CARE program of HIV care on the proportion of children with viral suppression (undetectable HIV RNA levels) and with HIV RNA $\geq 1,000$ copies/mL at 6 and 12 months after enrollment into the study.

2. Determine the individual and family factors associated with viral suppression and undetectable viremia in children 12 months after enrollment in FCCM and control facilities.

3. Evaluate the effect of a FAM-CARE program of HIV care on loss to follow-up (not seen in clinical care $>3$ months) and ART initiation in HIV-positive children not on ART at study entry.

4. Evaluate the acceptability of the FCCM program to caregivers and health care providers.

\section{STUDY DESIGN}

The FAM-CARE study was a two arm, prospective cohort study of HIV-positive children from selected facility sites implementing the FCCM program and control sites using the standard of care (separate adult and pediatric HIV care clinics) to assess the effects of the FCCM program on retention and viral suppression in HIV-positive children on ART. Program health care facility clusters were randomized to initiate the pilot FCCM program (two health care facility clusters) or continue to provide the current standard of HIV care with separate pediatric and adult HIV clinics (two health care facility clusters). The FAM-CARE study evaluated the effect of the program on pediatric viral suppression and retention in care using both quantitative and qualitative methods. Quantitative data collection included interviews conducted with caregivers to gather demographic, medical history, family history, HIV, and treatment history for caregivers, children, and other family 
members; medical chart abstraction to gather information on visit attendance, HIV treatment, pharmacy pick-up, and CD4 and viral load history if on ART for caregivers, children, and other family members; and collection of dried blood spot (DBS) specimens from children to test for viral load every six months. Data collection was conducted at enrollment and at every three months for children and caregivers, and every 6 months for other family members, for a minimum of 12 months after enrolment. Qualitative one-on-one in-depth interviews (IDIs) were conducted with randomly selected caregivers and with purposively selected health workers (HWs) at the FCCM sites to assess feasibility and acceptability of the FCCM program.

\section{Study setting and study population}

The FAM-CARE study sites were selected from PEPFAR-supported health facilities in Hhohho region, which consist of four clinic clusters consisting of a "parent" hospital or health center (Mbabane Government Hospital, Pigg's Peak Government Hospital, Emkhuzweni Health Centre, and Dvokolwako Health Centre clusters) and the local filter clinics that feed into the primary "parent" care center. For the FAM-CARE study, the four clusters and the accompanying largest filter clinic for each cluster were randomized to initiate the FCCM program (Emkhuzweni and Pigg's Peak clusters and their respective filter clinics Mangweni and Horo clinics) or to remain standard of care (Dvokolwako and Mbabane clusters and their respective filter clinics Balekane Nazarene and Lobamba clinics). Figure 1 shows the schema of study design for the evaluation of FCCM program (Appendix 1).

For the quantitative component, all children living with HIV under the age of 15 years receiving care at a study facility were eligible for enrollment in the prospective cohort regardless of treatment status if there was at least one other HIV-positive family member residing in the household receiving services at that facility. Children living with HIV were excluded from the study if they were attending care at a study facility only temporarily, they had no other HIV-positive family members in the household receiving services at the study facility, or the child or caregiver had a significant medical condition that would preclude active study participation. For the qualitative component, caregivers were eligible for IDIs if they were enrolled in the FCCM program at least 12 months prior to data collection and enrolled as a FAM-CARE study participant; HWs were eligible for IDI if they provided care in the FCCM site for at least 6 months prior to data collection.

\section{Sample size}

The sample size was powered to detect a difference in viral suppression (HIV RNA $\geq 1,000$ copies/ $\mathrm{mL}$ ) in children receiving ART in the FCCM sites to those receiving ART in control sites, with 80 percent power at 5 percent significance levels to detect at least a 10 percent increase in viral suppression with FCCM, assuming a suppression rate of 80 percent in the control sites, or a 15 percent increase in suppression if the control suppression rate was no more than 75 percent. Assuming 10 percent loss-to-follow-up, this required a sample of 444 HIV-positive children from unique families (222 from intervention sites and 222 from control sites). The study originally planned 18-month follow-up, but due to slower than expected enrollment, participants were followed up to 12 months, with exploratory analyses used for those children who had been followed up for 18 months to see if there were any differences in primary endpoints. 


\section{DESCRIPTION OF INTERVENTION}

The FCCM is a differentiated service delivery (DSD) model aimed at providing more efficient and effective HIV services to promote better ART initiation and retention in families. At sites randomized to implement FCCM, HIV-positive children were provided HIV services along with at least one other family member (HIV-positive or HIV-negative) involved in the support of the child. A family member was defined as someone related to the child either by blood or adoption, or someone residing in the same household who was responsible for the child. Family members had to be willing to disclose their HIV status to other family members within FCCM, attend clinic visits with the child, and support the child during clinic visits and at home. Family members living with HIV were invited to receive HIV care and treatment services at the same facility with the child, and HIV-negative family members received non-communicable disease health care services. All family members living with HIV were to be seen together in the facility and receive their care together as a family unit, with chronic care files kept in one family folder. ART medications were to be prepared for the family in advance of their visit and families were to be prioritized to be seen (or seen on special clinic "family days") to decrease waiting time. If all family members were stable, one family member could pick up medications for the entire family. Families in FCCM were seen at least once every quarter for family units with stable children as defined in the Eswatini Integrated HIV Management Guidelines 2018 for children. Families not meeting these criteria were seen monthly. For families with school-aged children, clinic visits were attempted to be scheduled around school holidays. Staff were trained in FCCM standard operating procedures (SOPs), which defined staff purpose, roles and responsibilities, and resources (Appendix 4 FCCM $\underline{\text { SOP }}$ and Appendix 5 Components of the FCCM Service Package).

\section{DATA COLLECTION METHODS}

All data collectors were trained by EGPAF research staff. A five-day training was held for study nurses who were responsible for collecting data in interviews and chart reviews. Qualitative interviewers were trained in a separate five-day training that included qualitative data collection methods and the qualitative data collection tools.

Following informed consent of the caregiver (and assent of children $>12-14$ years), data were collected through caregiver interviews and abstraction of facility, laboratory, and patient records using specific data collection forms. At enrollment, study nurses interviewed caregivers to collect demographic, medical, and HIV-related information about the caregiver, the child, and household members. Clinical laboratory data for caregivers, children, and other HIV-positive family members were abstracted from clinic medical records. Study nurses collected DBS specimens from children for viral load testing. Study follow-up visits were every three months for children and caregivers and were scheduled to coincide with routine clinic visits to the extent possible. At each study visit, study nurses obtained interim clinical history (e.g., medical/HIV history and CD4 count and, for children on treatment, ART history, current regimen, and adherence) through caregiver interview and medical chart abstraction. Data on clinic visit attendance and pharmacy drug pick-ups for children receiving ART were obtained by chart abstraction. DBS specimens were drawn from HIVpositive children on ART for study viral load testing every six months. Data collection activities are presented in Appendix 2. 
For the qualitative component, semi-structured one-on-one IDIs were conducted with caregivers and HWs to assess feasibility and acceptability of the FCCM. All interviews were conducted in a private room at the health facilities in the preferred language of participants, SiSwati. Interviews took place during October to December 2018 in the four health facilities implementing the pilot FCCM program (Appendix 3); one to four caregiver interviews were conducted at each site. Eligible caregivers were selected from a list of caregivers enrolled in both the FCCM program and the FAM-CARE study using a computer-aided simple random method. The FAM-CARE study nurse contacted the selected caregiver to return on a scheduled day for the interview and communicated with research assistants when the caregiver was scheduled for the interview. Caregivers returning to the facility for the purpose of the interview received transport reimbursement. Topics covered during the interviews included experiences engaging in the FCCM program, views on the advantages and disadvantages of FCCM, and perceptions of differences in the provision of care through FCCM compared to the standard of care. For HW interviews, FAMCARE study nurses worked with the site nurse-in-charge to identify eligible HWs (providers of care in the FCCM program $\geq 6$ months). If there were more HWs eligible than the range of IDIs selected for the facility, each HW was assigned a number and selected at random by lottery. The FAM-CARE study nurse contacted the selected HW and asked them to meet with the research assistant on a scheduled day for the interview. Interviews covered views on advantages and disadvantages of FCCM and barriers and facilitators in implementing the FCCM program.

\section{ETHICAL REVIEW}

The FAM-CARE study was reviewed and approved by Population Council Institutional Review Board (IRB) and the National Health Research Review Board in Eswatini.

\section{DATA ANALYSIS}

Demographic characteristics at enrollment were summarized using means (standard deviations) for continuous variables and proportions for categorical variables, stratified by FCCM intervention and control arms. Chi square tests of independence were used to identify any characteristics that differed significantly between the two study arms. The FCCM program decline rate was low $(<10 \%)$ and enrollment characteristics of children in FCCM and control sites were similar, thus a simple chi-square test was used to compare the two proportions at 5 percent significance level. An intention-to-treat analysis was performed in which all children at facilities offering the FCCM program were compared to all children at facilities without the FCCM program. To identify factors associated with viral suppression and undetectability, unadjusted bivariate and adjusted multilevel logistic regression models were developed to estimate the association between viral suppression and undetectable viremia, and putative factors in each study arm.

For the qualitative component, IDIs were audio recorded and transcribed in Microsoft Word, and simultaneously translated into English, by research assistants who conducted the interviews. The study team reviewed the transcripts and created a codebook based on the transcripts. Maxqda software was used to store and code transcripts. After coding was complete, data were summarized through descriptive, text-based summaries and tables by study investigators, 
identifying themes and patterns in the data. Results are presented by group (caregivers and HW) and summarized into overall findings. 


\section{KEY FINDINGS}

\section{QUANTITATIVE FINDINGS}

A total of 379 HIV-positive children under the age of 15 years (207 in the intervention arm and 172 in the control arm) from 363 unique families (203 in the intervention arm and 160 in the control arm) were enrolled in the study from September 2017 to July 2019. Table 1 shows the number of participants enrolled in the study by site and study arm. The unique families include 363 caregivers ( $97 \%$ living with HIV) and 28 other family members living with HIV (children and adults) living in the same household as the child and caregiver.

Table 1 Prospective cohort enrollment

\begin{tabular}{|c|c|c|c|c|c|}
\hline Facility name & Facility type & Study arm & $\begin{array}{c}\text { Unique families } \\
\text { enrolled }\end{array}$ & $\begin{array}{l}\text { Children } \\
\text { enrolled }\end{array}$ & $\begin{array}{c}\text { Other family } \\
\text { members } \\
\text { enrolled }\end{array}$ \\
\hline Pigg's Peak & Parent & Intervention & 61 & 62 & 3 \\
\hline Horo & Filter clinic & Intervention & 40 & 41 & 7 \\
\hline Emkhuzweni & Parent & Intervention & 58 & 59 & 8 \\
\hline Mangweni & Filter clinic & Intervention & 44 & 45 & 1 \\
\hline Dvokolwako & Parent & Control & 56 & 61 & 3 \\
\hline Bhalekane & Filter clinic & Control & 39 & 41 & 2 \\
\hline Mbabane & Parent & Control & 33 & 34 & 3 \\
\hline Lobamba & Filter clinic & Control & 32 & 36 & 1 \\
\hline Total & & & 363 & 379 & 28 \\
\hline
\end{tabular}

Table 2 shows demographic characteristics of children at enrollment. Nearly half of all children (47\%) were aged 5-9 years, one-third of children were aged 10-14 years and the rest were under the age of 5 years. Among children over age five years, 93 percent were in school. Of the children in school, 36 percent had missed school in the three months before enrollment; more children in the control than intervention group had missed school. 
Table 2 Demographic characteristics of HIV-positive children at enrollment

\begin{tabular}{|c|c|c|c|c|}
\hline Variable & $\begin{array}{c}\text { Control } \\
n=172 \\
n(\%)\end{array}$ & $\begin{array}{c}\text { Intervention } \\
\begin{array}{c}n=207 \\
n(\%)\end{array}\end{array}$ & $\begin{array}{c}\text { Total } \\
N=379 \\
n(\%)\end{array}$ & p-value \\
\hline \multicolumn{5}{|l|}{ Gender } \\
\hline Female & $81(47)$ & 106 (51) & 187 (49) & 0.43 \\
\hline Male & $91(53)$ & 101 (49) & 192 (51) & \\
\hline \multicolumn{5}{|l|}{ Age (years) } \\
\hline Mean (SD) & $8.1(4)$ & $8.6(4)$ & $8.4(4)$ & 0.20 \\
\hline $0-<1$ & $5(3)$ & $1(.05)$ & $6(2)$ & \\
\hline $1-<2$ & $5(3)$ & $2(1)$ & $7(2)$ & \\
\hline $2-<5$ & $27(16)$ & 35 (17) & $62(16)$ & \\
\hline $5-<10$ & $82(48)$ & $97(47)$ & $179(47)$ & \\
\hline $10-14$ & $53(31)$ & $72(35)$ & 125 (33) & \\
\hline \multicolumn{5}{|c|}{ Child in school ( $n=133$ control; $n=169$ intervention) } \\
\hline Yes & $125(94)$ & $155(92)$ & $280(93)$ & 0.45 \\
\hline No & $8(6)$ & $14(8)$ & $22(7)$ & \\
\hline \multicolumn{5}{|c|}{ Days missed school in past 3 months ( $n=125$ control; $n=155$ intervention) } \\
\hline Did not miss & $67(54)$ & $112(72)$ & $179(64)$ & 0.001 \\
\hline$<7$ days & $58(46)$ & $39(25)$ & $97(35)$ & \\
\hline $7-14$ days & $0(0)$ & $3(2)$ & $3(1)$ & \\
\hline $15-30$ days & $0(0)$ & $1(0.6)$ & $1(0.4)$ & \\
\hline
\end{tabular}

Less than a third of children (28\%) had ever been hospitalized. Most of the 106 children who had ever been hospitalized (76\%) had only been hospitalized once. Only six (6\%) children had been hospitalized three to five times. Since initiating HIV care, almost all children (98\%) had been continuously receiving care (Table 3 , next page).

At enrollment, 160 (42\%) of all children knew their HIV status. Figure 1 (next page) breaks disclosure down by age group: 102/122 (84\%) age 10-14 years knew their HIV status; 57/175 (33\%) age 5-9 years knew their HIV status; and almost all children under the age of 5 years were not aware of their HIV status. 
Table 3 HIV history of HIV-positive children at enrollment

\begin{tabular}{|c|c|c|c|c|}
\hline Variable & $\begin{array}{c}\text { Control } \\
n=172 \\
n(\%)\end{array}$ & $\begin{array}{c}\text { Intervention } \\
\begin{array}{c}n=207 \\
n(\%)\end{array}\end{array}$ & $\begin{array}{c}\text { Total } \\
\text { N=379 } \\
n(\%)\end{array}$ & p-value \\
\hline \multicolumn{5}{|c|}{ Ever been hospitalized } \\
\hline Yes & $51(30)$ & $55(27)$ & $106(28)$ & \multirow[t]{3}{*}{0.24} \\
\hline No & $121(70)$ & $149(72)$ & $270(71)$ & \\
\hline Other & $0(0)$ & $3(1)$ & $3(0.8)$ & \\
\hline \multicolumn{5}{|c|}{ Number of hospitalizations ( $n=46$ control; $n=50$ intervention) } \\
\hline 1 & $35(76)$ & $38(76)$ & $73(76)$ & \multirow[t]{3}{*}{0.55} \\
\hline 2 & $9(20)$ & $8(16)$ & $17(18)$ & \\
\hline $3-5$ & $2(4)$ & $4(8)$ & $6(6)$ & \\
\hline \multicolumn{5}{|c|}{ After entering HIV care, child continually in care } \\
\hline Yes & $171(99)$ & $202(98)$ & $373(98)$ & \multirow[t]{3}{*}{0.33} \\
\hline No & $1(0.6)$ & $4(2)$ & $5(1)$ & \\
\hline Other & $0(0)$ & $1(0.5)$ & $1(0.3)$ & \\
\hline \multicolumn{5}{|c|}{ Child knows HIV status } \\
\hline Yes & $83(48)$ & $77(37)$ & $160(42)$ & \multirow[t]{3}{*}{0.03} \\
\hline No & $83(48)$ & $127(61)$ & $210(55)$ & \\
\hline Other & $6(4)$ & $3(1)$ & $9(2)$ & \\
\hline \multicolumn{5}{|c|}{ Child currently on ART ( $n=206$ intervention) } \\
\hline Yes & $171(99)$ & $207(100)$ & $378(99.7)$ & \multirow[t]{2}{*}{ NS } \\
\hline No & $1(0.6)$ & $0(0)$ & $1(0.3)$ & \\
\hline
\end{tabular}

Figure 1 Children's awareness of HIV status by age and group at enrollment

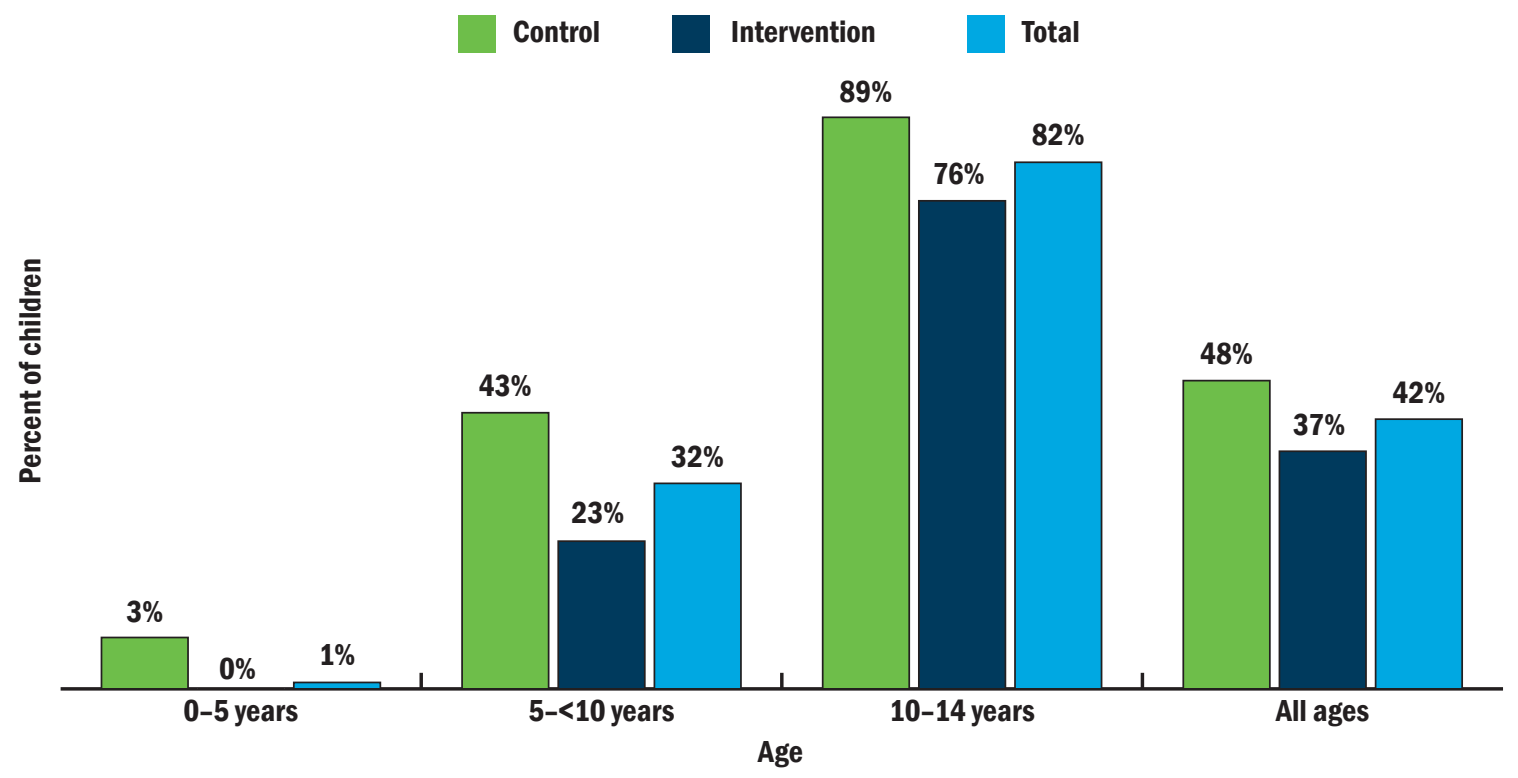


All children were receiving ART at enrollment except one child. Figure 2 shows ART regimen type for children at enrollment. The majority of children were on zidovudine (AZT)+lamivudine (3TC)+nevirapine (NVP) (39\%). Other regimens included, abacavir (ABC)+3TC+lopinavir/ritonavir (LPV/R) (19\%), ABC+3TC+efavirenz (EFV) (17\%), AZT+3TC+LPV/r (10\%) and AZT+3TC+EFV (6\%). In the year before enrollment, 30 percent of children had reported treatment interruptions.

\section{Figure 2 Treatment regimen for children receiving ART at enrollment}

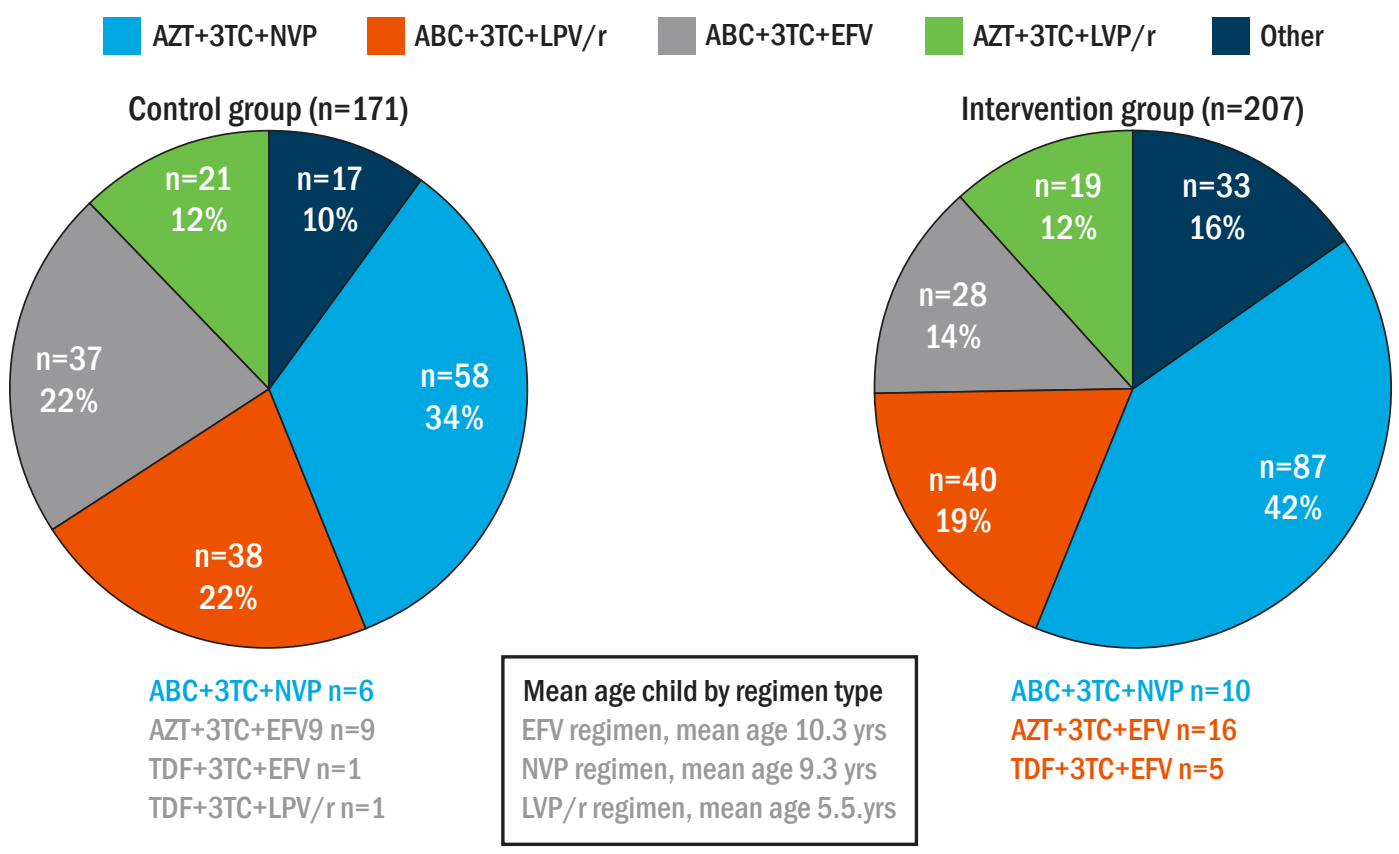

At enrollment, 60 percent of children were adhering well (>95\% doses) to their ART regimen, with only 6 percent with poor adherence $(<85 \%)$ (Figure 3, next page). In the last 7 days before enrollment, 10 percent of children had missed their ART drugs at least once. A total of 85 percent of children had their last two ART refill pick-ups on time.

At enrollment, 78 percent of children had achieved viral suppression $(<1,000 \mathrm{copies} / \mathrm{mL})(80 \%$ intervention and $77 \%$ control, $p=0.68$ ) and 74 percent of children had undetectable viremia ( $<400$ copies $/ \mathrm{mL}$ ) (76\% intervention and $72 \%$ control, $p=0.51)$. Factors associated with viral suppression at enrollment were child's age and ART regimen. Viral suppression was most likely among older versus younger children, with 82 percent in children aged 10-14 years; 80 percent in children aged $5-9$ years; 74 percent in children aged $2-5$ years; and 46 percent in children under age 2 years. Viral suppression was higher among those children on EFV-based regimen (87\%) compared to NVP-based regimens (73\%) and LPV/r-based regimens (79\%).

Of the 363 caregivers who enrolled in the study, 92 percent were women (Table 4, next page). Women caregivers were significantly younger than men caregivers (mean age ( $\mathrm{min}, \mathrm{max}$ ): 35 $(15-73)$ versus $40(27-67)$ years. About half of the caregivers were married or living together as a couple, 33 percent had never been married, 11 percent were widowed and 3 percent were divorced. 


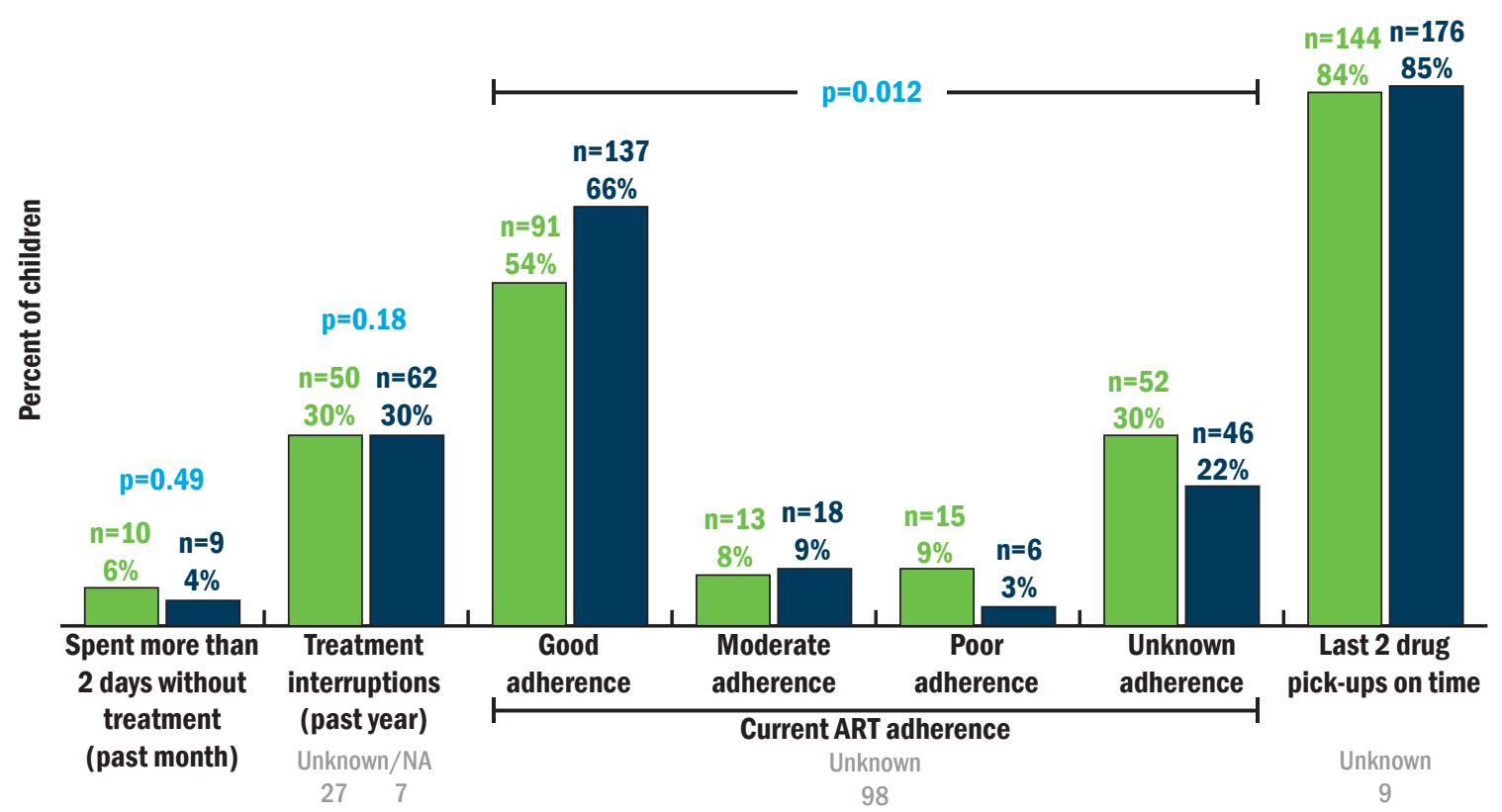

Table 4 Caregiver demographic characteristics at enrollment

\begin{tabular}{|c|c|c|c|c|}
\hline Variable & $\begin{array}{c}\text { Control } \\
n=160 \\
n(\%)\end{array}$ & $\begin{array}{c}\text { Intervention } \\
n=203 \\
n(\%)\end{array}$ & $\begin{array}{c}\text { Total } \\
N=363 \\
n(\%)\end{array}$ & $p$-value \\
\hline \multicolumn{5}{|l|}{ Age (years) } \\
\hline Median (range) & $35(15-70)$ & $36(21-73)$ & $35.5(15-73)$ & NS \\
\hline \multicolumn{5}{|l|}{ Gender } \\
\hline Female & $147(93)$ & $186(92)$ & $333(92)$ & 0.77 \\
\hline Male & $13(8)$ & $17(8)$ & $30(8)$ & \\
\hline \multicolumn{5}{|l|}{ Education } \\
\hline Never attended & $20(13)$ & 31 (15) & $51(14)$ & 0.22 \\
\hline Primary & $67(42)$ & $68(34)$ & $135(37)$ & \\
\hline Secondary & $59(37)$ & $71(35)$ & $130(36)$ & \\
\hline Beyond secondary & $14(9)$ & $33(16)$ & $47(13)$ & \\
\hline \multicolumn{5}{|l|}{ Marital status } \\
\hline Married & $65(41)$ & $95(47)$ & $160(44)$ & 0.45 \\
\hline Living with partner & $9(6)$ & $12(6)$ & $21(6)$ & \\
\hline Single & $60(38)$ & 59 (29) & 119 (33) & \\
\hline Divorced/Widowed/Separated & $26(16)$ & $37(18)$ & $63(17)$ & \\
\hline
\end{tabular}

Nearly all of the caregivers (97\%) were living with HIV at enrollment (Table 5). About 41 percent of caregivers' households had more than one adult living with HIV, and 10 percent had more than one child living with HIV in the household. 
Table 5 Caregiver HIV history at enrollment

\begin{tabular}{|c|c|c|c|c|}
\hline Variable & $\begin{array}{c}\text { Control } \\
n=160 \\
n(\%)\end{array}$ & $\begin{array}{c}\text { Intervention } \\
\begin{array}{c}n=203 \\
n(\%)\end{array}\end{array}$ & $\begin{array}{c}\text { Total } \\
N=363 \\
n(\%)\end{array}$ & p-value \\
\hline \multicolumn{5}{|l|}{ HIV status } \\
\hline Positive & $153(96)$ & $198(98)$ & $351(97)$ & \multirow[t]{2}{*}{0.31} \\
\hline Negative & $7(4)$ & $5(3)$ & $12(3)$ & \\
\hline \multicolumn{5}{|c|}{ Number of HIV+ adults in caregiver household including caregiver } \\
\hline 0 & $4(3)$ & $2(1)$ & $6(2)$ & \multirow[t]{3}{*}{0.55} \\
\hline 1 & $87(54)$ & $122(60)$ & $209(58)$ & \\
\hline $2+$ & $69(43)$ & $79(39)$ & $148(41)$ & \\
\hline \multicolumn{5}{|c|}{ Number of HIV+ children in caregiver household } \\
\hline 1 & $143(89)$ & $184(91)$ & $327(90)$ & \multirow[t]{3}{*}{0.56} \\
\hline 2 & $13(8)$ & $16(8)$ & $29(8)$ & \\
\hline $3-4$ & $4(3)$ & $3(2)$ & $7(2)$ & \\
\hline \multicolumn{5}{|c|}{ Number of HIV+ members on ART in caregiver household including caregiver and child } \\
\hline 1 & $88(55)$ & $121(60)$ & $209(57)$ & \multirow[t]{3}{*}{0.74} \\
\hline 2 & $61(38)$ & $71(35)$ & $132(36)$ & \\
\hline $3+$ & $11(7)$ & $11(5)$ & $22(6)$ & \\
\hline
\end{tabular}

All caregivers living with HIV were receiving ART at enrollment (Figure 4). At enrollment, 62 percent of caregivers were receiving tenofovir disoproxil fumarate (TDF)+3TC+EFV, 21 percent were on AZT+3TC+NVP, and the rest were on other regimens. Most caregivers receiving ART were on EFV-based regimens, 25 percent were on NVP-based regimens, and 4 percent were on LPV/Rbased regimens with NRTI backbones of ABC, AZT, or TDF plus 3TC.

Figure 4 ART regimen of caregivers at enrollment

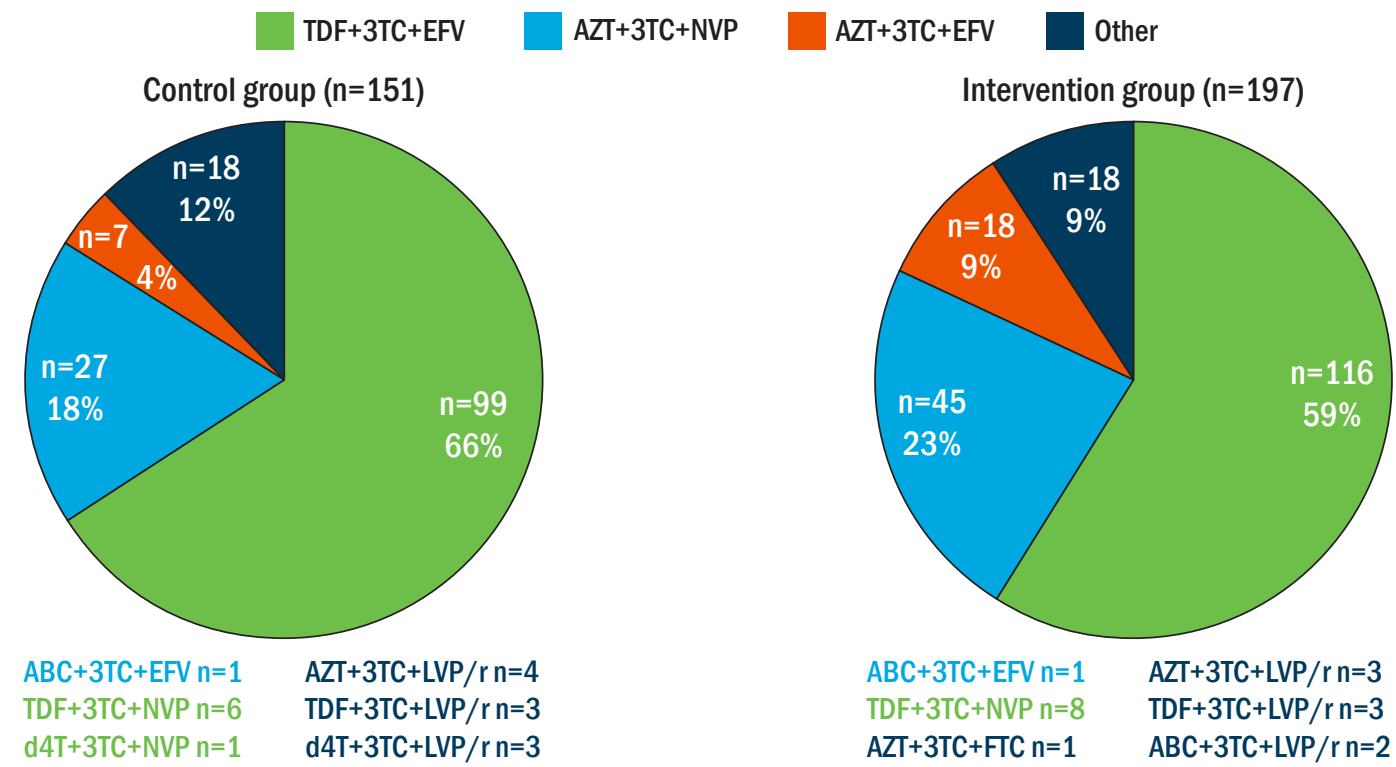




\section{Viral suppression among HIV-positive children during study}

The total number of children with viral load test results decreased over time from 375 (100\%), 337 (90\%), 346 (84\%), and 216 (58\%) at enrollment, 6, 12, and 18 months, respectively, with no significant difference between study groups. There was no statistically significant difference in viral suppression or detectability by study arm at 12 or 18 months. Overall, viral suppression improved between enrollment and 12 months follow up in both arms, from 78 percent at enrollment ( $80 \%$ intervention, $77 \%$ control) to 90 percent at 12 months (89\% intervention, $92 \%$ control); and was 87 percent at 18 months (91\% intervention, $83 \%$ control). The overall proportion of children who achieved undetectable viral load increased from 74 percent at enrollment $76 \%$ intervention, $72 \%$ control) to 87 percent at 12 months (88\% intervention, $86 \%$ control) and 84 percent at 18 months ( $86 \%$ intervention, $82 \%$ control).

\begin{tabular}{|c|c|c|c|c|}
\hline Variable & $\begin{array}{c}\text { Control } \\
n=172 \\
n(\%)\end{array}$ & $\begin{array}{c}\text { Intervention } \\
n=207 \\
n(\%)\end{array}$ & $\begin{array}{c}\text { Total } \\
N=379 \\
n(\%)\end{array}$ & p-value \\
\hline \multicolumn{5}{|l|}{ Viral suppression at enrollment } \\
\hline HIV RNA <1,000 copies/ mL & $130(77)$ & $164(80)$ & $294(78)$ & \multirow[t]{2}{*}{0.41} \\
\hline HIV RNA $\geq 1,000$ copies/mL & $40(24)$ & $41(20)$ & $81(22)$ & \\
\hline \multicolumn{5}{|c|}{ Viral suppression at 12-month follow-up } \\
\hline HIV RNA <1,000 copies/ mL & $120(92)$ & $165(89)$ & $285(90)$ & \multirow[t]{2}{*}{0.48} \\
\hline HIV RNA $\geq 1,000$ copies/mL & $11(8)$ & $20(11)$ & $31(10)$ & \\
\hline \multicolumn{5}{|c|}{ Viral suppression at 18-month follow-up } \\
\hline HIV RNA <1,000 copies/ mL & $88(83)$ & $100(91)$ & $188(87)$ & \multirow[t]{2}{*}{0.08} \\
\hline HIV RNA $\geq 1,000$ copies/mL & $18(17)$ & $10(9)$ & $28(13)$ & \\
\hline \multicolumn{5}{|c|}{ Undetectable viremia at enrollment } \\
\hline HIV RNA <400 copies/ mL & $122(72)$ & $155(76)$ & $277(74)$ & \multirow[t]{2}{*}{0.40} \\
\hline HIV RNA $\geq 400$ copies/ mL & $48(28)$ & $50(24)$ & $98(26)$ & \\
\hline \multicolumn{5}{|c|}{$\begin{array}{l}\text { Undetectable viremia at 12-month follow- } \\
\text { up }\end{array}$} \\
\hline HIV RNA <400 copies/ mL & $113(86)$ & $163(88)$ & $276(87)$ & \multirow[t]{2}{*}{0.63} \\
\hline HIV RNA $\geq 400$ copies/ mL & $18(14)$ & $22(12)$ & $40(13)$ & \\
\hline \multicolumn{5}{|c|}{$\begin{array}{l}\text { Undetectable viremia at 18-month follow- } \\
\text { up }\end{array}$} \\
\hline HIV RNA<400 copies/ mL & $87(82)$ & $94(86)$ & $181(84)$ & \multirow[t]{2}{*}{0.50} \\
\hline HIV RNA $\geq 400$ copies/ mL & $19(18)$ & $16(15)$ & $35(16)$ & \\
\hline
\end{tabular}

Among the 252 children who had viral suppression at enrollment, 97 percent remained suppressed at 12 months follow up (98\% intervention, 95\% control, $p=0.23$ ); and 62 percent of children who were unsuppressed at enrollment achieved viral suppression at 12 months follow up (54\% intervention, $75 \%$ control, $p=0.10$ ); there were no significant differences between study groups (Table 7). 
Table 7 Viral suppression in children at 12- and 18-month follow-up by viral suppression status at enrollment

\begin{tabular}{|c|c|c|c|}
\hline Variable & $\begin{array}{c}\text { Control } \\
\text { n (\%) }\end{array}$ & $\begin{array}{c}\text { Intervention } \\
\mathrm{n}(\%)\end{array}$ & $\begin{array}{l}\text { Total } \\
\text { n (\%) }\end{array}$ \\
\hline \multicolumn{4}{|c|}{ Among children suppressed at enrollment, viral suppression at 6-month follow-up } \\
\hline HIV RNA <1,000 copies/mL & $108 / 113(96 \%)$ & $143 / 150(95 \%)$ & $251 / 263(95 \%)$ \\
\hline \multicolumn{4}{|c|}{ Among children not suppressed at enrollment, viral suppression at 6-month follow-up } \\
\hline HIV RNA <1,000 copies/mL & $14 / 31(45 \%)$ & $14 / 40(35 \%)$ & 28/71 (39\%) \\
\hline \multicolumn{4}{|c|}{ Among children suppressed at enrollment, viral suppression at 12-month follow-up } \\
\hline HIV RNA $<1,000$ copies/ mL & $101 / 106(95 \%)$ & $143 / 146(98 \%)$ & $244 / 252(97 \%)$ \\
\hline \multicolumn{4}{|c|}{ Among children not suppressed at enrollment, viral suppression at 12-month follow-up } \\
\hline HIV RNA $<1,000$ copies/mL & $18 / 24(75 \%)$ & $20 / 37(54 \%)$ & $38 / 61(62 \%)$ \\
\hline
\end{tabular}

\section{Factors associated with viral suppression and undetectable viremia}

In unadjusted bivariate analyses among all children at 12 months after enrollment, several factors were significantly associated with viral suppression (HIV RNA $<1,000$ copies/mL). Children who were not aware of their HIV status tended to be less likely than children who were aware of their HIV status to be virally suppressed (OR:0.46; 95\% Cl: 020, 1.08). Compared to children with caregivers under age 25 years, children with older caregivers aged 30-40 years (OR: 5.53; 95\% Cl: $1.80,17.00$ ) and aged $>40$ years (OR: $3.93 ; 95 \% \mathrm{Cl}: 1.30,11.85)$ were significantly more likely to be suppressed. Most caregivers were living with HIV, with only 12 caregivers being HIVnegative. The odds of suppression among children with HIV-negative caregivers were significantly lower than the odds of suppression among children with HIV-positive caregivers (OR: 0.15; 95\% Cl: 0.05, 0.49). At study entry, children on NVP-based ART had significantly lower levels of viral suppression (73\%) than those on EFV-based (87\%) or LPV/r-based ART (79\%) ( $p=0.04)$. While rates of viral suppression at 12 months after enrollment remained lowest in those on NVPbased ART (87\%) compared to EFV-based ART (94\%) and LPV/r-based (91\%) ART, this was not statistically significant $(p=0.31)$. Study intervention versus control group was not statistically significantly associated with viral suppression at 12 months $(p=0.48)$ or 18 months $(p=0.08)$ after enrollment.

In unadjusted bivariate analyses among all children at 12 months, similar factors were associated with undetectable viremia (HIV RNA $<400$ copies/ $\mathrm{mL}$ ). The odds of undetectable viremia tended to be lower among children who did not know their HIV status compared to children who did know their HIV status (OR: $0.55 ; 95 \% \mathrm{Cl}: 0.26,1.14, \mathrm{p}=0.10$ ). Children in the care of older caregivers aged $30-40$ years (OR: $5.24 ; 95 \% \mathrm{Cl}: 1.83,15.04$ ) and older than 40 years (OR:3.15; 95\% $\mathrm{Cl}: 1.14,8.68)$ were more likely to have undetectable viremia than children in the care of younger aged caregivers aged under 25 years. Children in the care of HIV-negative caregivers versus HIVpositive caregivers were less likely to have undetectable viremia (OR:0.15; 95\% $\mathrm{Cl}$ : 0.05, 0.46). The odds of undetectable viremia were significantly lower among children in households with three or more HIV-positive children versus children in households with two or fewer HIV-positive children (OR: 0.21; 95\% Cl: 0.06, 0.78). Although undetectable viremia at 12 months after enrollment was lowest among children on NVP-based ART (84\%) compared to EFV-based (90\%) and LPV/r-based (89\%) ART, this was not statistically significant $(p=0.38)$. Study intervention 
versus control group was not statistically significantly associated with undetectable viremia at 12 months $(p=0.63)$ or at 18 months follow $(p=0.38)$.

There was an association of age with suppression and undetectable viral load. Overall, 93 percent of children aged 10-14 years had viral suppression at 12 months follow up compared with 88 percent of children aged 5-9 years and 76 percent of children aged under 5 years. Similarly, undetectable viral load was observed in 91 percent of children aged 10-14 years, 87 percent of those aged 5-9 years, and 81 percent of those aged under 5 years. There was not a significant difference in the levels of suppression or detectability by intervention versus control group when stratified by age.

\section{Retention in care, adherence, interruptions in ART care, and HIV disclosure}

There were no significant differences between intervention and control groups in retention in care, interruption of ART, or reported adherence or disclosure at 12 months (Table 8). At 12 months of follow-up, 93 percent of children expected to be seen at the 12-month visit had a documented clinic visit, with no significant difference between groups (91\% intervention, 94\% control, $p=0.53)$. At the 12-month visit, ART interruption was reported by 16 percent in the intervention and 15 percent in the control groups ( $p=0.82$ ); good adherence was reported by 84 percent in the intervention and 87 percent of the control groups ( $p=0.32$ ); and last two drug pick-ups were reported to be on time for 88 percent of intervention and 92 percent of control group children $(p=0.18)$. The proportion of children who did not know their HIV status at enrollment but learned their HIV status during the study was low and not statistically different between groups (6\% intervention and $5 \%$ control. $p=0.69$ ). In the more limited sample of 216 children with 18-month follow-up, 12 percent reported ART interruption, 93 percent reported good ART adherence, and 87 percent reported last two drug pick-ups were on time, with no significant differences between groups.

Table 8 Retention, adherence, and disclosure for children living with HIV during the study

\begin{tabular}{|c|c|c|c|c|}
\hline Variable & $\begin{array}{l}\text { Control } \\
n(\%)\end{array}$ & $\begin{array}{l}\text { Intervention } \\
\mathrm{n}(\%)\end{array}$ & $\begin{array}{l}\text { Total } \\
\text { n (\%) }\end{array}$ & p-value \\
\hline \multicolumn{5}{|l|}{ 12-month visit retention } \\
\hline $\begin{array}{l}\text { Number with clinic visit/number } \\
\text { expected for visit }\end{array}$ & $152 / 161(94)$ & $178 / 195$ (91) & $330 / 356$ (93) & 0.31 \\
\hline \multicolumn{5}{|l|}{ 12-month visit ART adherence* } \\
\hline ART interruption since last visit & 19/131 (15) & 26/168 (16) & $45 / 299$ (15) & 0.82 \\
\hline Good reported adherence & 95/109 (87) & $102 / 121(84)$ & $197 / 230(86)$ & 0.32 \\
\hline Last 2 drug pick-ups on time & $134 / 145(92)$ & $153 / 174(88)$ & $287 / 319(90)$ & 0.18 \\
\hline \multicolumn{5}{|l|}{ New disclosure during study** } \\
\hline $\begin{array}{l}\text { New HIV disclosure to children who } \\
\text { did not know status at enrollment }\end{array}$ & $4 / 79(5)$ & $8 / 125(6)$ & $12 / 204(6)$ & 0.69 \\
\hline
\end{tabular}

*Data missing for ART interruption for 55/354 (16\%) children (30/161 control, 19\%; 25/193 intervention, 13\%); ART adherence 124/354 (35\%) children (52/161 control, 32\%; 72/193 intervention, 37\%); and drug pick up for 35/319 (11\%) children (16/161 control, 6\%; 19/193 intervention, 10\%)

**Data on child disclosure status at enrollment were available for 370/379 (98\%) children, with 210 undisclosed; data on subsequent disclosure were available for 204/210 (97\%) (79/83 control, 95\%, and 125/127 intervention, 98\%) 


\section{QUALITATIVE FINDINGS}

In this section of the report, key findings from semi-structured interviews with caregivers and health workers engaged in the FCCM program are presented. Key themes are described in the following order: demographic characteristics of caregivers and HWs, benefits of FCCM, challenges in participating in FCCM and in implementation, and recommendations for improving the FCCM model in the Eswatini context.

\section{Characteristics of semi-structured interview participants}

Semi-structured interviews were conducted with 25 caregivers participating in the FCCM program in four intervention sites. Table 9 presents caregiver demographic data. Of the 25 caregivers, only two were men, most were married or cohabitating (17 of 25), and the mean age was 37.8 years. The child and caregiver were the only family members enrolled in the FCCM program in 19 of the 25 caregiver households, and 16 caregivers were the biological parent of the child. All of the caregivers and their children were HIV-positive and on ART at the time they were interviewed for the study.

Table 9 Caregiver demographic characteristics
\begin{tabular}{|lc|}
\hline Variable & Caregivers \\
$n=25$ \\
$n(\%)$
\end{tabular}
\begin{tabular}{lc} 
Age (years) & Mean $=37.8$ \\
Gender & $(26-63)$ \\
Female & \\
Male & $23(92)$ \\
Education & $2(8)$ \\
Primary and lower & $12(48)$ \\
Beyond primary & $13(52)$ \\
Marital status & \\
Never married & $10(32)$ \\
Married, non-polygamous & $19(40)$ \\
Married, polygamous & $4(16)$ \\
Cohabitating & $3(12)$ \\
Employment status & $25(100)$ \\
Unemployed & $19(76)$ \\
Employed & $6(24)$ \\
Relationship to child & \\
Caregiver currently on ART & \\
member & \\
\hline
\end{tabular}


A total of 17 health workers were interviewed for the FAM-CARE study; their demographic data are shown in Table 10. Most of the HWs were women (14 of 17) and had some secondary education (12 of 17). Most common roles of the HWs interviewed were midwife or expert client.

\section{Benefits of FCCM}

Caregivers said that they felt that FCCM strengthened the family bond. FCCM was perceived as encouraging family members to disclose their HIV status to other family members, including to male partners and the child. Caregivers said they felt this helped to reduce stigma within the family by encouraging family members to talk more openly about living with HIV and taking ARV drugs. If one family member forgets to take their medication, another family member can remind them. Caregivers also viewed their disclosure with their children

Table 10 Health worker characteristics

\begin{tabular}{|lc|}
\hline Variable & $\begin{array}{c}\text { Health worker } \\
n=17 \\
n(\%)\end{array}$ \\
Gender & \\
Female & $14(82)$ \\
Male & $3(18)$ \\
Education & \\
Secondary & $2(12)$ \\
High school & $1(6)$ \\
Tertiary & $14(82)$ \\
Current role in health facility & \\
Midwife & $6(35)$ \\
Expert client & $6(35)$ \\
Nursing sister & $2(12)$ \\
Senior nurse & $1(6)$ \\
General nurse & $1(6)$ \\
Nursing assistant & $1(6)$ \\
\hline
\end{tabular}
as a positive way for the child to see that the caregiver is also living with HIV and taking their medication, motivating the child to continue to participate in FCCM and take their medication. Caregivers said that for some men, participating in FCCM helped them in their caregiver role and to support women and children in the family in HIV care and treatment.

Another thing is that there is no more hiding from each other to take pills on time. Even my child is always reminding us that it is now time to take pills so we do things together. No one to say, eish...now it is time for medication, the child also knows the dates. Even in January the child will come again for the next visit. The family is always free to do things together. It is like a game to us now because we are happy.

-Female caregiver, age 29 , of boy age 8

Caregivers also viewed FCCM as having practical benefits in saving time. Caregivers liked the "fast tracking" where, as participants in FCCM they were moved to the front of the line. This reduced time at the facility typically spent waiting in line.

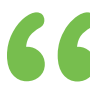
... I am now more comfortable unlike before when I would think of going to the facility, I would first think of the long lines and would be irritated in one way or the other. The FCCM patients are the ones provided with services first, and they always tell us to come early in the morning as we are the first clients to be taken care of.

-Female caregiver, age 43, of boy age 13

Caregivers' perceived the FCCM program to offer better counseling than the counseling provided in the standard of care, and that HWs in FCCM were taking "good care" of them. Patient files in FCCM were viewed by caregivers as being kept more confidentially than in the standard of care. Caregivers liked that FCCM provided call reminders for upcoming visits and the fact that they saw the same HW at each clinic visit. 
When I used to come before I was enrolled in FCCM they would just count my pills,

but now when I come I would always talk to a nurse in a certain room [who would] ask me how do I feel, how is the child doing on his treatment. Then that would make me feel happier to get such a warm welcome from a health care worker.

-Female caregiver, age 28, of girl age 7

And what I like with FCCM program is that, if there is one member who doesn't drink the medication or doesn't adhere, the HW are able to correct our mistakes, motivate us and encourage us together as a family.

-Male caregiver, age 40, of girl age 13

HWs said the FCCM program enabled them to gather and track family histories, identify family challenges to HIV care and treatment, and identify long-lasting solutions. HWs said FCCM facilitated communication among family members, encouraging individuals to share more of their needs together with other family members. Meeting with caregivers and their children together provided an opportunity for HWs to assist caregivers in disclosing their HIV status to the child. HWs liked having patient files for each family pulled ahead of time and grouped together for the clinic visit.

Addressing them as a family is much better because everyone will say their side they want to talk about, they don't talk about each other. When they are together there will be some transparency. They will be able to talk to each other. It has also helped us with disclosure, even if the mother was scared to tell the child, they can now tell the child as a family.

-Female health care worker, age 37

HWs said FCCM improved the patient-provider communication and relationship, where patients could ask questions of providers and were more actively seeking information during clinic visits.

\section{Challenges in FCCM}

Caregivers had to incur additional costs for clinic visits for multiple family members, as FCCM required the family to visit the clinic together. There were schedule conflicts with clinic visits for school-aged children attending school and weekend teen support groups. It was also difficult for some caregivers to encourage men in their families to participate in FCCM because men did not want to get an HIV test. Caregivers also said that sometimes in the facility when they could step to the front of the line as part of the "fast tracking" of FCCM participants, other clients in the waiting room criticized them and complained.

At some facilities, HWs said that some families did not attend clinic visits together as a family unit. Some families rotated family members to come pick up medication for the whole family. HWs also noted that some families were food insecure and children would skip taking their medication because taking it on an empty stomach made them feel sick. 
HWs also had challenges with managing larger groups of family members at the same time and experienced staff shortages. HWs said sometimes family members did not get along and this was difficult to manage. When there were larger groups and staff members were seeing multiple clients at one time, the clinic visits took longer, and some facilities did not have enough staff to cover the visits.

While caregivers said FCCM encouraged disclosure, many HWs saw disclosure as a challenge of implementing FCCM. Disclosure in the context of the family was difficult for many family members because of the fear of what other family members or partners would think of them and fear of family members gossiping about them to others. Many children were not aware of their HIV status because caregivers were unable to fully disclose the child's status.

As the disclosure has been a problem, parents were anxious on how they will tell their children... they cannot disclose well.

-Female health care worker, age 54

66 But then the challenge that I have is that my son keeps asking me when will he stop taking the pills? He always says that he is tired of taking the pills, the child further says that he is not sick, he feels better now.

-Female caregiver, age 28 , of boy age 10

In particular, both HWs and caregivers said that encouraging men to participate in FCCM was a challenge. Some men were hesitant to receive HIV testing and counseling as part of the FCCM program. Both caregivers and health workers mentioned difficulty in discussing sensitive health information in the presence of other family members. For HWs, it was a challenge to ask sensitive questions, such as asking adolescents about their sexual activity in the presence of their caregiver or asking caregivers about reproductive health and family planning use in front of their children.

\section{Recommendations for FCCM strengthening and scale-up}

Most participants felt that the FCCM program should be continued and scaled-up nationally. The FCCM program was well-liked by participants, who thought the program should continue and should be expanded to other communities. Scale-up was recommended by participants because they perceived the program provided benefit in reducing stigma within the family and promoted more open discussion about HIV and HIV disclosure within the family. Participants said that the encouragement to disclose helped family members support one another in adherence to ART and clinic appointments. For some families, FCCM saved money in transport costs in attending clinic visits.

HWs stated they would like more training on how to ask sensitive questions within the context of a family clinic visit and how to offer counseling to caregivers to disclose their HIV status to family members and to children, and to disclose the child's HIV status to the child. HWs also wanted more training in how to manage family dynamics and what to do if family members do not get along. 
HWs suggested adding a social worker to the FCCM provider team to address psychosocial needs of families in HIV care and treatment. The FCCM does not currently include a social worker. To address the additional work burden and extended time of the clinic visit for HWs to see multiple family members in one visit, HWs suggested increasing the number of staff at the facility on FCCM clinic days.

Caregivers and HWs suggested designating specific days for FCCM clients only, to reduce the amount of time FCCM clients wait in line if they are not "fast tracked" to the front. Both caregivers and HWs also suggested preparing the families' medications ahead of the clinic visit so family members do not have to wait in long pharmacy lines to receive their medication.

Another suggestion was to offer other types of care such as screening tests for blood sugar levels or taking care of other health concerns such as head or stomach pain, during the FCCM clinic visit. Seeing the same nurse at each visit and adding more FCCM staff with specific roles and responsibilities were suggested by both caregivers and HWs for improving service delivery. HWs reported an increased work burden to provide care to families rather than to individual clients during clinic visits. The FCCM clinic visits take longer and some HWs said their facility did not have sufficient staff to cover these longer visits and attend other clients; thus, adding staff for FCCM programming would improve wait times during the FCCM clinic visits. 


\section{DISCUSSION}

The study arm was not significantly associated with viral suppression or undetectable viremia at 12 (or 18) months after enrollment. Participation in FCCM did not show any statistically significant improvements in retention, adherence, ARV drug refill pick-ups, or children who knew their HIV status versus control groups. In the control arm, high proportions of children had achieved viral suppression, retention, and adherence. In order to detect a difference in these outcomes, a significantly larger sample size would have been required.

Analysis of enrollment data demonstrated that factors associated with lack of viral suppression included younger age ( $<5$ years) and treatment regimen, with children receiving NVP-based ART significantly less likely to have viral suppression. When children are on a suboptimal regimen, they are less likely to achieve viral suppression. These results highlight the importance of programs in Eswatini and elsewhere to monitor treatment regimens as children age and ensure WHO guidelines for treatment regimens are implemented to optimize pediatric outcomes. Following mid-study analysis of enrollment data demonstrating that a significant proportion of children were receiving suboptimal ART, EGPAF developed a briefing sent to all EGPAF countries regarding the need to review and optimize ART regimens in all children (Appendix 6). These data were also published in Pediatric Infectious Disease Journal to get wider dissemination of the critical need to continually review ART regimens to ensure optimization of ART in children as they age up (Chouraya et al. 2019)

Caregivers and HWs involved in FCCM discussed both benefits and challenges of FCCM in qualitative interviews. Caregivers perceived improved adherence, retention in care, and overall health of children in the program. HWs said FCCM encouraged HIV disclosure and support for adherence among family members. However, HWs said that timing of teen support groups and school schedules were not coordinated well with clinic visits. There was a lack of fidelity to the FCCM model noted, with some sites reporting that families did not attend clinic visits together as a family, but rotated family members to come get medication for the whole family. Both caregivers and HWs had difficulties in discussing sensitive health information in the presence of other family members. According to FCCM program data, only 40 percent of all 465 families enrolled in the program at the pilot sites actually attended at least one clinic visit together as a family, and only 26 percent of families attended clinic visits together four times a year. Attendance at FCCM was not related to age of the child; similar proportions of families with a child under 10 years of age (42\%) versus with a child at least 10 years of age (38\%) attended at least one clinic visit together as a family. Families enrolled in FCCM with only two members living with HIV (e.g., caregiver and child) were more likely to have attended at least one clinic visit as family than those with more than two family members living with HIV (47\% versus $20 \%$, respectively).

Results from the quantitative data reflect the challenges discussed in qualitative interviews. One of the challenges of participating in FCCM was schedule conflicts with school and teen support groups. Because of these challenges, caregivers with older children may have been less likely to attend clinic visits with their child than caregivers with younger children. Both HWs and caregivers 
said they had difficulty discussing sensitive health information in the presence of other family members. For older children and their caregivers, these factors may have been more of a barrier to attend clinic visits together than caregivers with younger children. However, children aged at least 10 years had the highest rates of viral suppression compared to younger children; 12-month suppression was 94 percent and undetectable viral load was 91 percent. Understanding the role of teen support groups in improving viral suppression and adherence among adolescents compared to FCCM or similar family-centered care models would be helpful. While this suggested to us that perhaps FCCM may be most effective among the younger children, when doing a stratified analysis by age under 5 years, $5-9$ years and more than 10 years, there did not appear to be a differential effect of FCCM on viral suppression by age, with suppression and undetectability not significantly different between FCCM and control children, regardless of age.

Children who did not know their HIV status tended to be in the care of younger caregivers and have HIV-negative caregivers and were less likely to achieve viral suppression at 12 months after enrollment. Supplemental training for health providers engaged in FCCM in how to support caregivers in disclosing the child's HIV status could improve the proportion of children who know their HIV status, a need specifically noted by HWs in the qualitative component of the study. Adolescent or young adult caregivers may need additional support in caring for children living with HIV, including administration of the recommended ART regimens, adhering to clinic visit schedules, and HIV disclosure to the child. Providers may need additional training in counseling and identifying the needs of younger caregivers to be able to effectively support and counsel them. The complex psychosocial needs identified by HWs who participated in semi-structured interviews and their recommendation to have social workers added to the care team reflects an important gap in adequately addressing structural and social barriers within the family that can affect HIV outcomes for children.

PEPFAR guidance stipulates that "differentiated care and innovative service delivery (DSD) models should focus on populations that have difficulty with retention, such as children, adolescents, young adults, men, pregnant women, and key populations. Adherence programs should be focused on the clients with elevated viral loads and not generic programs to all clients." The FCCM program is considered a DSD service delivery model for children and families. One of the lessons learned through implementing the FCCM is that children older than 10 years prefer peer to peer support through the teen support groups rather than being accompanied by caregivers to clinic appointments. The model is also helpful for those on treatment failure (caregivers and children) to better monitor and counsel caregivers and children in adherence. Drug dispensing should be aligned to the extent possible for stable caregivers and children so that they are able to attend FCCM visits on the same schedule. These lessons learned align with PEPFAR guidance on DSD and multi-month dispensing of medication.

\section{LIMITATIONS}

There are several limitations to the study. Given slower than expected enrollment, the overall sample size was lower than planned (379 versus 444). Slow enrollment resulted in reducing the follow-up time from 18 to 12 months in order to adhere to the study timeline, with only 57 percent of children followed for the full planned 18 months, limiting the power of the study to detect differences between study arms for children over time. Additionally, given the high levels 
of viral suppression, retention, and adherence at baseline in both FCCM and control children, it would have required a significantly larger sample size to be able to detect a difference in these outcomes with the FCCM program. 


\section{CONCLUSION AND RECOMMENDATIONS}

\section{CONCLUSIONS}

Children had high levels of viral suppression and undetectable viremia at enrollment, which further improved by 12 months after enrollment, with no significant differences between FCCM intervention and control groups. Factors associated with viral suppression at 12 months after study entry included child's awareness of their HIV status, caregiver's age, and caregiver's HIV status, with similar factors associated with undetectable viremia.

Enrollment data demonstrating that a significant proportion of children were receiving suboptimal NVP-based ART, which was associated with lower levels of viral suppression, were important to direct attention to the critical need to review and optimize ART regimens in all children as they age up and more potent and less toxic regimens may become available.

Overall, caregivers and health workers who participated in semi-structured interviews liked the FCCM program and valued the services received through the program. Caregivers felt FCCM promoted disclosure to other family members, reducing HIV stigma and encouraging adherence support for each other. Caregivers perceived FCCM as improving both ART adherence and retention in care, as well as the overall health of the child. HWs viewed FCCM as improving patient-provider communication and facilitating tracking patient histories. Challenges were also discussed. Caregivers reported scheduling conflicts with school schedules and teen support group meetings. HWs noted poor fidelity to the FCCM intervention, with some families not attending clinic visits together as a family as a whole, but rather rotating family members to come to the facility to pick up medication for all family members. Both caregivers and HWs had difficulties with sharing sensitive health information in the presence of other family members.

Given the favorable view by caregivers and HWs, the government of Eswatini plans to implement the FCCM as one of the DSD models for HIV care for families. These findings highlight important considerations for improving pediatric HIV care as well as FCCM programs for younger-aged caregivers and HIV-negative caregivers, and for HWs in supporting caregivers in disclosing HIV status to children. Given the high rates of suppression in older children, evaluation of the effects of teen support clubs on HIV pediatric outcomes could illuminate how sufficient teen support groups are in ensuring ART adherence and viral suppression among older children. Based on these findings, specific recommendations are provided here for consideration in planning for national scale up of FCCM in Eswatini. These findings and recommendations may apply to similar country contexts in sub-Saharan Africa. 


\section{RECOMMENDATIONS}

As the Eswatini Ministry of Health plans for FCCM program scale up, several important recommendations based on these study findings could improve program implementation and thus achieve better pediatric HIV outcomes. These recommendations would be able to improve implementation of the FCCM program and are also relevant to pediatric HIV care in general:

- Continue to ensure access to treatment regimen and viral load monitoring in order to optimize pediatric treatment regimens.

- Provide additional training to health providers in counseling and support to caregivers for HIV disclosure to the child and to other family members.

- Provide additional counseling and support for younger caregivers (<25 years of age) with children in HIV care and treatment.

- Provide additional support to caregivers who have younger children in HIV care and treatment, where rates of viral suppression are lower.

- Revise the FCCM SOPs and programming to aid implementation with fidelity:

- Improve coordination of the timing of FCCM clinic visits for school-aged children to better accommodate school and teen support group schedules.

- FCCM is most appropriate for children younger than age 10 years and their caregivers, and for caregivers and children experiencing treatment failure. Children 10 years and older benefit more from peer to peer support through the teen support clubs.

- Disclosure is only assessed once during the clinic visits, at enrollment. Disclosure should be assessed at different time points along the cascade as the child's understanding of their HIV diagnosis changes over time.

- At enrollment see all family members, conduct baseline assessment to ascertain if families need frequent monitoring or less.

- For stable families, visits can be scheduled quarterly aligning with school holidays.

- Align caregiver and child's schedule for drug dispensing for stable patients, and advocate and mentor health care workers to offer multiple month refills for children.

- Ensure the number of families with appointments are manageable in a day. Family appointments should be distributed across several days as opposed to all families visiting health facilities on a single day. Appointments should be based on family sizes.

- Include additional training for health providers in counseling and talking to adults about sensitive health topics in the context of the family and in managing larger groups during clinic visits.

- Add social workers to the FCCM care team to address psychosocial needs of program participants.

- Evaluate the effects of teen support groups on ART adherence and viral suppression in older children. 


\section{REFERENCES}

Beatancourt, Theresa S., Elaine J. Abrams, Ryan McBain, Mary C. Smith Fawzi. 2010. "Family-centered approaches to the prevention of mother-to-child transmission of HIV," Journal of the International AIDS Society 13 (Suppl 2): S2. doi: 10.1186/1758-2652-13-S2-S2

Bonner, Kimberly et al. 2013. "Viral load monitoring as a tool to reinforce adherence: a systematic review," Journal of Acquired Immune Deficiency Syndromes 64: 74-78. doi: 10.1097/QAI.0b013e31829f05ac

Chouraya, C. et al. 2019. "Association of antiretroviral drug regimen with viral suppression in HIV-positive children on antiretroviral therapy in Eswatini," Pediatr Infect Dis J. 38: 835-839.doi: 10.1097/INF.0000000000002347

Davies, Mary-Ann et al. 2011. "Virologic failure and second-line antiretroviral therapy in children in South Africa: the IeDEA Southern Africa Collaboration," Journal of Acquired Immune Deficiency Syndromes 56(3): 270-278. doi: 10.1097/QAl.0b013e3182060610

Dufort, Elizabeth M. et al. 2017. "Misclassification of antiretroviral treatment failure using WHO 2006 and 2010/2013 immunololgic criteria in HIV-infected children and adolescents in western Kenya," Journal of Pediatric Infectious Diseases Society 6(3): 285-288. doi: 10.1093/ipids/piw018

Hosegood, Victoria and Sangeetha Madhavan. 2010. "Data availability on men's involvement in families in subSaharan Africa to inform family-centered programmes for children affected by HIV and AIDS," Journal of the International AIDS Society 13 (Suppl 2): S5.doi: 10.1186/1758-2652-13-S2-S5

Jobanputra, Kiran et al. 2015. "Factors associated with virologic failure and suppression after enhanced adherence counseling in children, adolescents, and adults on antiretroviral therapy for HIV in Swaziland," PLosOne 10: e0116144. doi: 10.1371/journal.pone.0116144

Joint United Nations Program on HIV/AIDS. The Gap Report. Geneva, Switzerland: World Health Organization, 2014. Retrieved 28 October 2019 (https://www.unaids.org/en/resources/documents/2014/20140716_UNAIDS gap report).

Leeper, Sarah C., Brian T. Montague, Jennifer F. Friedman and Timothy P. Flanigan. 2010. “Lessons learned from family-centered models of treatment for children living with HIV: current approaches and future directions," Journal of the International AIDS Society 13(Suppl 2): 53. doi: 10.1186/1758-2652-13-S2-S3

Luyirka, Emmanuel et al. 2013. "Scaling-up pediatric HIV care with an integrated, family-centered approach: an observational case study from Uganda," PLosOne 8(8): e69548. doi: 10.1371/journal.pone.0069548

Maman, David et al. 2016. "Closer to 90-90-90. The cascade of care after 10 years of ART scale-up in rural Malawi: a population study," Journal of the International AIDS Society 19: 20673. doi: 10.7448/IAS.19.1.20673

McMahon, James H. et al. 2013. "Viral suppression after 12 months of antiretroviral therapy in low- and middleincome countries: a systematic review," Bulletin of the World Health Organization 91: 377-85E. doi: 10.2471/ BLT.12.112946

Myer, Landon et al. 2014. "Family matters: co-enrollment of family members into care is associated with improved outcomes for HIV-infected women initiating antiretroviral therapy," Journal of the International AIDS Society 67(Suppl 4): S243-249. doi: 10.1097/QAI.0000000000000379

Pillay, V., M-A Davies, S. King, and B. Eley. 2015. "Short-term treatment outcomes of children starting antiretroviral therapy in the intensive care unit, general medical wards and outpatient clinics at Red Cross War Memorial Children's Hospital, Cape Town, South Africa: a retrospective cohort study," South African Medical Journal 105: 220-227. doi: 10.7196/samj.8950

Puga, D. et al. 2016. "Still far from 90-90-90: virologic outcomes of children on antiretroviral therapy in nurse-led clinics in rural Lesotho," Pediatric Infectious Disease Journal 35: 78-80. doi:: 10.1097/INF.0000000000000929

Richter, L., C. Beyrer, S. Kippax, and S. Heidari. 2010. "Visioning services for children affected by HIV and AIDS through a family lens," Journal of the International AIDS Society 13(Suppl 2): I1. doi: 10.1186/1758-2652-13-S2$\underline{11}$

Roberts, Teri, Jennifer Cohn, Kimberly Bonner, and Sally Hargreaves. 2016. “Scale-up of routine viral load testing 
in resource-poor settings: current and future implementation challenges," Clinical Infectious Diseases 62: 10431048. doi: $10.1093 /$ cid/ciw001

Rochat, Tamsen Jean et al. 2011. "Towards a family-centered approach to HIV treatment and care for HIV-exposed children, their mothers and their families in poorly resourced settings," Future Virology 6: 687-696. doi: 10.2217/ fvl.11.45

Towne-Gold, Besigin et al. 2009. "Implementing family-focused HIV care and treatment: the first 2 years' experience of the mother-to-child transmission-plus program in Abidigan, Cote d'Ivoire," Tropical Medicine in International Health 14: 204-12. doi: 10.1111/i.1365-3156.2008.02182.x

World Health Organization. 2014. 90-90-90: An ambitious treatment target to help end the AIDS epidemic. Geneva, Switzerland: World Health Organization. Retrieved 28 October 2019 (https://www.unaids.org/en/ resources/documents/2017/90-90-90).

World Health Organization. 2016. Consolidated guidelines on the use of antiretroviral drugs for treating and prevention HIV infection: recommendations for a public health approach, $2^{\text {nd }}$ edition. Geneva, Switzerland: World Health Organization. 


\section{APPENDICES}

\section{APPENDIX 1 \\ SCHEMA OF STUDY DESIGN FOR THE EVALUATION OF FAM-CARE PROGRAM DESIGN}

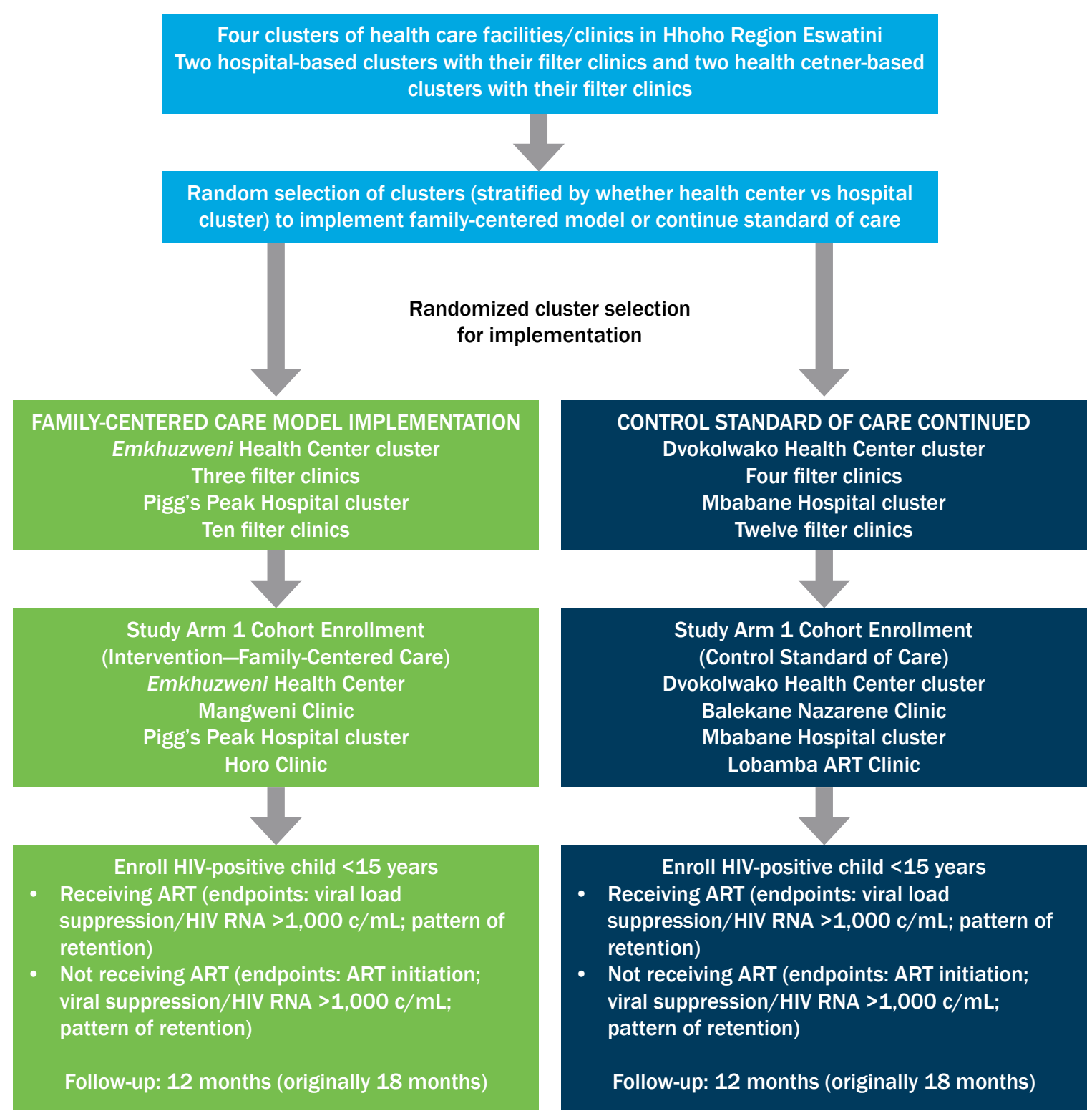




\begin{tabular}{|c|c|c|c|c|c|c|c|}
\hline \multirow[t]{2}{*}{ Data collection } & \multirow[t]{2}{*}{ Enrollment } & \multicolumn{6}{|c|}{ Months } \\
\hline & & 3 & 6 & 9 & 12 & 15 & 18 \\
\hline \multicolumn{8}{|l|}{ All children living with HIV } \\
\hline Demographic data & $x$ & \multirow{7}{*}{$\begin{array}{l}x \\
x \\
x\end{array}$} & & \multirow{7}{*}{$\begin{array}{l}x \\
x \\
x\end{array}$} & & \multirow{7}{*}{$\begin{array}{l}x \\
x \\
x \\
x\end{array}$} & \\
\hline HIV and ART history & $x$ & & & & & & \\
\hline $\begin{array}{l}\text { Current ART regimen (regimen, } \\
\text { adherence, drug pick-up) }\end{array}$ & $x$ & & $x$ & & $x$ & & $x$ \\
\hline Interim (between visits) HIV history & & & $x$ & & $x$ & & $x$ \\
\hline CD4 count (medical chart abstraction) & $x$ & & $x$ & & $x$ & & $x$ \\
\hline $\begin{array}{l}\text { Medical visit attendance timeliness/ } \\
\text { missed visits }\end{array}$ & & & $x$ & & $x$ & & $x$ \\
\hline Viral load test (drawn for study) & $x$ & & $x$ & & $x$ & & $x$ \\
\hline \multicolumn{8}{|l|}{$\begin{array}{l}\text { Caregivers and other family members } \\
\text { living with HIV }\end{array}$} \\
\hline Demographic data & $x$ & \multirow{4}{*}{$x$} & & \multirow{4}{*}{$x$} & & \multirow{4}{*}{$x$} & $x$ \\
\hline Family HIV history & $x$ & & & & & & \\
\hline $\begin{array}{l}\text { HIV+ caregiver ART and viral load } \\
\text { history (interview and medical chart } \\
\text { abstraction) }\end{array}$ & $x$ & & $x$ & & $x$ & & $x$ \\
\hline $\begin{array}{l}\text { HIV+ family member ART and viral } \\
\text { load history (interview and medical } \\
\text { chart abstraction) }\end{array}$ & $x$ & & $x$ & & $x$ & & $x$ \\
\hline
\end{tabular}

*Collected any time a child was initiated on ART (on ART at entry or starts ART during study)

\section{APPENDIX 3}

\section{IDIS CONDUCTED IN EACH FAM-CARE PROGRAM SITE}

\begin{tabular}{|c|c|c|c|c|}
\hline Facility name & Facility type & $\begin{array}{l}\text { Facility } \\
\text { ownership }\end{array}$ & $\begin{array}{c}\text { Number of caregivers } \\
\text { interviewed }\end{array}$ & $\begin{array}{c}\text { Number of HWs } \\
\text { interviewed }\end{array}$ \\
\hline Pigg's Peak Government & Hospital & Public & 9 & 7 \\
\hline Horo & Clinic & Public & 5 & 3 \\
\hline Emkhuzweni & Health center & Public & 7 & 5 \\
\hline Mangweni & Clinic & Public & 4 & 2 \\
\hline Total & & & 25 & 17 \\
\hline
\end{tabular}




\section{APPENDIX 4 \\ FIVE STEPS IN PROVIDING FCCM FROM FCCM STANDARD OPERATING PROCEDURES (SOP)}

1. Sensitization of clients about FCCM

The expert clients, HTS counselors, and nurses included FCCM during the health talks in the morning and during one-on-one counseling using FCCM sensitization script.

\section{Enrollment into FCCM}

Expert clients identified eligible index children already receiving HIV care or treatment services and invited eligible family members for enrollment into the FCCM directly by using the FCCM invitation letter or through a phone call. The family unit folder was created, the program enrollment form completed, and all individual chronic care files retrieved for all family members and put into the family folder. Each family folder was given an FCCM number that was also documented on the patient booklet. Invitations for index testing were provided by the HTS counselors on their return.

3. Organization of family folders and scheduling family appointments

Nurses scheduled follow up appointments for all individuals in the family unit enrolled in FCCM on the same day and completed documentation in the chronic care file and patient booklet. The expert client completed documentation of the family appointment date into the appointment register, and the expert client or data clerk refiled the family folder according to the family unit number in the designated filing cabinet. Appointment reminders were sent to the family 3 days before their appointment visit.

4. Family follow up visits before arrival at the facility

The expert clients and data clerks retrieved all family folders for families scheduled for a particular day and the nurse reviewed the individual chronic care files to request or follow up particular lab tests, results, or other care as needed. Medications were prepared for family units at two clinics (Horo and Mangweni). However, at Emkhuzweni Health Centre and Pigg's Peak Hospital, pending authorization for drug distribution in the hospitals and health centers, prescriptions were written and dispensed on the day of the visit.

5. Family follow up visits on arrival at the facility

Family units were "fast tracked" to the expert client on arrival, circumventing some of the lines for receiving care, and documentation was updated in the appointment register. 


\section{APPENDIX 5}

\section{FAM-CARE PACKAGE OF SERVICES}

\begin{tabular}{|c|c|}
\hline & ART clinic \\
\hline & $\begin{array}{l}\text { Multi-disciplinary team: AIDSFree mentors, facility doctors, nurses, expert clients, social workers, } \\
\text { HTS counselor, phlebotomist, pharmacy personnel, data clerks }\end{array}$ \\
\hline \multicolumn{2}{|c|}{ Service provided } \\
\hline $\begin{array}{l}\text { Clinic } \\
\text { visits }\end{array}$ & $\begin{array}{l}\text { 1. Family-centered assessment of adherence } \\
\text { 2. Family-centered adherence support } \\
\text { 3. Family counseling and assisted disclosure support } \\
\text { 4. Patient education in the context of the family to increase patient adherence, treatment, and } \\
\text { viral load literacy in preparation for long term adherence +/- a change in ART regimen. } \\
\text { 5. Medical history and examination } \\
\text { 6. Screening and treating comorbidities/opportunistic infections } \\
\text { 7. Refill ARVs and prophylactic medications (CTX, IPT, Fluconazole) and adjust ART doses and } \\
\text { 8. Laboratory monitoring } \\
\text { 9. Index testing for family members for ART initiation } \\
\text { 10. Referrals for other services (social worker support, nutritional support, cervical cancer }\end{array}$ \\
\hline
\end{tabular}




\section{APPENDIX 6 \\ EGPAF EVIDENCE TO ACTION: URGENT UPDATE! OPTIMIZING PEDIATRIC REGIMENS BRIEF}

Available on next page and available for download here: https://www.pedaids.org/resource/

optimizing-pediatric-regimens/. 


\section{Evidence to Action: Urgent Updatel}

\section{OPTIMIZING PEDIATRIC REGIMENS}

Implementation of new and improved pediatric antiretroviral formulations is required to better address the needs of children infected with HIV. Too many children are receiving nevirapine (NVP)-based antiretroviral therapy (ART), even though NVP is no longer recommended as a preferred first-line treatment for children by the World Health Organization (WHO), due to associated risk of drug resistance. EGPAF's FAM-CARE Study in Eswatini showed that, more than three years after Eswatini switched to the WHO-recommended efavirenz (EFV)-based first-line ART in children aged over 3 years, more than $43 \%$ of children were still receiving NVP-based ART, while less than one third (26\%) were on EFV-based ART. FAM-CARE looked at a range of factors, including demographics; age at initiation; duration of and adherence to ART; and interruptions to care, and found that the only factor significantly associated with lack of viral suppression in children was receiving a NVP-based regimen.

As a leader in pediatric HIV care and treatment, EGPAF must play an important role in global efforts to optimize pediatric ART outcomes. We have demonstrated that more focus is needed in actually implementing the WHO pediatric treatment guidelines and ensuring the children we serve are promptly initiated on, and transitioned to, the most optimal ART regimens. Standardizing implementation of more efficacious ART regimens, in line with the latest 2018 WHO pediatric treatment guidelines, is a high priority for EGPAF. This document aims to help our programs better articulate why this change is urgently needed, to advocate for policy and service delivery shifts, and to overcome challenges to fully implement these guidelines in diverse settings.

\section{KEY FACTS ABOUT NEW GLOBALLYRECOMMENDED TREATMENT GUIDELINES}

The 2018 WHO pediatric treatment quidelines recommend several key shifts, which are outlined in the 2018 Optimal Formulary and Limited-Use List for Paediatric ARVs:

- Due to increasing prevalence of non-nucleoside reverse transcriptase (NNRTI) resistance, transitioning from NNRTI-based ART, such as NVP or EFV, to integrase strand transfer inhibitor (INSTI)-based ART, such as dolutegravir (DTG) and raltegravir (RAL), for first-line treatment is now recommended.

- A shift from using age limits to using weight bands to determine ART formulations and dosing for children is needed.

- For children who weigh at least $25 \mathrm{~kg}$, DTG-based regimens are now the preferred first-line ART, with guidelines likely to suggest use for those weighing at least $20 \mathrm{~kg}$.

- For children and infants under $25 \mathrm{~kg}$, lopinavir-ritonavir (LPV/r)-based ART is the recommended first-line treatment until appropriate DTG dosing is defined for young children.

- For newborns, RAL is now recommended as the preferred first-line treatment (instead of NVP-based ART) due to its ability to rapidly reduce viral load (VL). RAL is the only INSTI with approved dosing for infants and young children. However, because RAL has a lower barrier to resistance, the guidelines recommend using it for the shortest time possible.

- Infants are able to switch from RAL to LPV/r liquid or granules starting at 2 weeks of age; or infants can switch to LPV/r pellets at 3 months of age. Solid LPV/r formulations are generally preferred due to the poor taste and low tolerability of liquid LPV/r. Where solid LPV/r formulations are not available, RAL can be used in infants as an alternative regimen. 
Table 1. WHO Recommended ART Regimens for Neonates and Children

\begin{tabular}{|c|c|c|}
\hline & Neonates & Children \\
\hline Preferred Treatment Regimen & $\mathrm{AZT}+3 \mathrm{TC}+\mathrm{RAL}^{1}$ & $\mathrm{ABC}+3 \mathrm{TC}+\mathrm{DTG}^{1}$ \\
\hline Alternative & $\mathrm{AZT}+3 \mathrm{TC}+\mathrm{NVP}$ & $\begin{array}{l}\mathrm{ABC}+3 \mathrm{TC}+\mathrm{LPV} / \mathrm{r}^{2} \\
\mathrm{ABC}+3 \mathrm{TC}+\mathrm{RAL}{ }^{1}\end{array}$ \\
\hline $\begin{array}{l}\text { Special Circumstances } \\
\text { (Only In Cases Where No Other } \\
\text { Alternative Is Possible) }\end{array}$ & $\mathrm{AZT}+3 \mathrm{TC}+\mathrm{LPV} / \mathrm{r}$ & $\begin{array}{l}A B C+3 T C+E F V^{3} \\
A Z T+3 T C+E F V^{3} \\
A Z T+3 T C+L P V / r \\
A Z T+3 T C+N V P \\
A Z T+3 T C+R A L \\
A B C+3 T C+R A L\end{array}$ \\
\hline
\end{tabular}

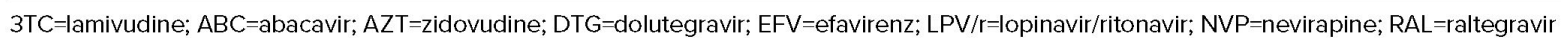

Because of lower barrier to resistance than other INSTI drugs, use RAL for the shortest time possible, until a solid formulation of LPV/r or DTG can be used.

${ }^{2}$ Until DTG is approved for younger children, $\mathrm{ABC}+3 \mathrm{TC}+\mathrm{LPV} / \mathrm{r}$ is the preferred regimen for children ages 2 weeks to $6 \mathrm{years}$ and $<15 \mathrm{~kg}$.

EFV should only be used in children three years or older.

\section{STEPS TO GAIN MOMENTUM IN SWITCHING CHILDREN TO APPROPRIATE FORMULATIONS}

1. Promote EGPAF leadership and Ministry of Health $(\mathrm{MOH})$ awareness

2. Support $\mathrm{MOH}$ to revise treatment guidelines, if needed

3. Prepare for site-level implementation of the revised guidelines

4. Reevaluate forecasting to ensure adequate ARV stocks at national and sub-national levels

5. Monitor and document the transition

\section{PROMOTE EGPAF LEADERSHIP AND MINISTRY OF HEALTH (MOH) AWARENESS}

Talking points to use with $\mathrm{MOH}$ staff and other partners:

- Global targets call for $95 \%$ of HIV-positive children to be virally suppressed by 2030 ; current studies imply that rates for viral suppression among HIV-positive children on ART hover around $75 \%$. We will not reach $95 \%$ viral suppression in children if they are on sub-optimal regimens.

- According to recently published EGPAF study results, the number one factor associated with low suppression rates in children is suboptimal ART regimen: NVP-based regimens are significantly less likely to produce sustained viral suppression and are also more likely to result in drug resistance with non-adherence.

- Children are the most vulnerable population and the future of our countries. We are not doing our job to provide effective care and treatment for them if we don't prioritize the implementation of currently-recommended, evidence-based HIV treatment guidelines.

- Recognizing more effective drugs are now available in appropriate formulations for newborns, infants and children, the WHO recommends all countries move to DTG-based ART for children $>6$ years who weigh $>15 \mathrm{~kg}$ and to use LPV/r-based regimens for children ages 2 weeks to under $<6$ years who weigh $<25 \mathrm{~kg}$.

- Let's carefully review the revised WHO pediatric treatment guidelines (updates to these guidelines will be available in June 2019) to guide revision and inform immediate roll-out of revised national guidelines to ensure the best treatment outcomes for children.

- COP guidance states that PEPFAR will no longer purchase NVP-based regimens for use in country for any age group.

- Although many countries changed their guidelines following a WHO mandate in 2015 , there is still a significant gap in site-level implementation. 


\section{SUPPORT MOH TO REVISE TREATMENT GUIDELINES, IF NEEDED}

- Ensure that national ART guidelines are aligned with the 2018 WHO pediatric treatment recommendations.

- Promote change, when needed, by calling on technical working group committee involvement.

- Country programs should be familiar with and consider national regulatory and local availability status of specific dosage forms when developing national pediatric treatment guidelines.

- Guidance should address VL testing for those transitioning to a different regimen. Ideally, children should have VL test sample collected before they switch to a new regimen, without switch delay. If a child has had a VL test done within 3 to 6 months preceding the ART change, there is no need for repeat VL before the switch. Instead, VL monitoring should continue after the switch, as per the national treatment monitoring algorithm.

\section{PREPARE FOR SITE-LEVEL IMPLEMENTATION OF THE REVISED GUIDELINES}

- Determining the proportion of children receiving sub-optimal ART regimens and rapidly assessing transition needs can be done through development of a nationally adapted, pediatric treatment cohort tool (see guidance in Table 2).

- Determine which sites serve pediatric ART populations. Work with these sites to better describe their pediatric cohort, including the spectrum of the ages and weight bands, and current treatments prescribed and distributed. Support sites to assess what changes are required for transition to new regimens.

- Train health care workers on the revised ART guidelines and visit sites to provide mentorship and support. Ideally, schedule site visits with $\mathrm{MOH}$ and site managers.

- Health care workers will also require support to improve routine VL testing. This is an area of weakness in pediatric populations and often prevents health care workers from ensuring all children are on optimal regimens and virally suppressed.

- Site-level managers should also be re-trained and supported around site inventory.

- Develop appropriate job aids for health care workers on the revised ART guidelines and develop a simple algorithm for them to switch children to optimal ART regimens effectively, while also managing a shift in treatment stock supply. EGPAF's New Horizons Project has an excellent resource on this: http://www.pedaids.org/resource/ new-horizons-management-of-treatment-failure-for-pediatric-and-adolescent-patients-resource-package/

\section{Table 2. Development of a Pediatric Treatment Cohort Tool}

EGPAF country programs should develop a tool that is aligned with their national guidelines. Suggested considerations are listed below.

Considerations for regimen transition

- Which ARVs will be used for which ages/weights?

- Are improved formulations available in-country?

- Are fixed-dose combinations available?

- Do dosage forms need to be adapted?

- Current regional/site stock of ARVs including formulations

- Regional/site ARV stock needed for transition based on country guidelines.

\section{Considerations for data collection}

- Date of ART initiation

- First ART regimen

- Weight at ART initiation

- Current age and weight (or weight band)

- Current ART regimen (including dosage and formulation)

- Date changed to current regimen

- Treatment status (active, last VL test, VL results, suppressed or not, etc.)

- History of TB

Contact EGPAF's TAS team (TASTeam@pedaids.org) to request assistance, if needed. 


\section{REEVALUATE FORECASTING TO ENSURE ADEQUATE ARV STOCKS AT NATIONAL AND SUB-NATIONAL LEVELS}

- Use the pediatric treatment cohort tool you have developed to improve site-level assessment of ARV stocks, including pediatric formulations.

- Effective forecasting requires site-level identification of the numbers of children currently on ART stratified by weight and age through facility registers, while line-listing those who need to be switched to the preferred regimens.

- Support the $\mathrm{MOH}$ in selecting the various drugs combinations and formulations they will procure based on what is in the guidelines.

- Forecasting should consider the estimated number of infants and children who will need to be switched to LPV/r-based regimen (from NVP) and the number of older children ( $>25 \mathrm{~kg}$, and potentially $>20 \mathrm{~kg}$ ) who will need to be switched to a DTG-based regimen.

- Fixed-dose combination (FDC), when available, are preferable for pediatric populations. FDCs for the dual NRTI backbone are likely already in the procurement plans (e.g., ABC/3TC), so forecasting should prioritize these drugs and formulations as well as the new ones that are being rolled out.

- The only FDC available for children is the dual formulation of ABC/3TC, because tenofovir disoproxil fumarate (TDF)/3TC is available only in adult dosing (TDF $300 \mathrm{mg}$ ), which is too large a dose for children $<30 \mathrm{~kg}$

- Sites will also need to procure single tabletDTG $50 \mathrm{mg}$, which may have occurred already in some sites as TB/HIV co infected patients should receive a double dose of DTG (50 mg twice daily) due to interactions between DTG and rifampin. The $50 \mathrm{mg}$ formulation is critical for dosing children starting at $25 \mathrm{~kg}$ of weight (or potentially $20 \mathrm{~kg}$ ). Accurate forecasting will be essential to procure stand-alone $50 \mathrm{mg}$ DTG tablets.

\section{MONITOR AND DOCUMENT THE TRANSITION}

- Since documentation of current and changing pediatric regimens will be critical, programs should prioritize meeting with national $\mathrm{MOH}$ representatives to support the development and roll-out of revised clinic registers and web-based databases, where available, and build the use of the new registers into health care worker trainings.

- While it would be ideal from programs to collect baseline data on the number of children on each ART regimen for comparison (which could be done under the Patient and Program Outcomes Protocols [PPOPs], email your HQ Research Support Person for more details), it is critical for EGPAF programs to at least document how many children need to be and have transitioned to the preferred regimens. This is NOT currently a PEPFAR indicator, but it will be an important data point to highlight to PEPFAR and our donors in reports and presentations. This data will also be useful for monitoring the transition.

- There are many VL testing gaps across sites, programs, and countries, especially in pediatric populations. To ensure we're rolling out the new ART guidelines effectively for children, we need to improve treatment outcome (e.g., VL) monitoring. Children should not only be accessing optimal first-line regimens, but second- and thirdline regimens when needed. Therefore, transition to new ART regimens should be paired with improving VL testing uptake and utilization of VL test results in practice with timely interventions.

- Since experience with DTG among children is limited, the WHO recommends that routine toxicity monitoring be ensured when this recommendation is implemented. Health care workers must also be trained on reacting to adverse events as they monitor toxicity. 


\section{KEY CONSIDERATIONS AROUND DOSING AND COUNSELING CLIENTS ON CORRECT FORMULATIONS:}

- Dispersible tablets (or granules for oral solution) are preferred formulations for children, because tablets/ granules can be made into liquid at the time of administering the drug to the child. If suitable dispersible formulations are not available and oral liquids must be used, it is recommended that children be switched to a solid oral dosage form (e.g., granules, pellets, dispersible tablets), as soon as possible.

- Administration of ART to neonates generally necessitates use of oral liquid formulations, switching to solid oral dosage form as soon as possible is recommended (e.g., switch from RAL to LPV/r granules at 2 weeks of age or LPV/r pellets at 3 months of age).

- Use of scored tablets are preferred to ensure accurate dosing (splitting of unscored tablets - such as LPV/r heat-stable ${ }^{1}$ tablets - should be avoided as uniform distribution of active drug product cannot be assured and bioavailability of the drug within the body may be decreased)

- Infants younger than 3 months of age should be prioritized for LPV/r oral solution.

- Infants and young children between 3 months - 3 years of age should be prioritized for starting or switching to LPV/r oral pellets or granules.

- The age at which children are able to swallow LPV/r $(100 \mathrm{mg} / 25 \mathrm{mg})$ heat-stable tablets varies between 3 and 5 years. Therefore, estimate that about half $(50 \%)$ of children 3 to 5 years of age will continue to use LPV/r pellets or granules and another half (50\%) will be able to swallow LPV/r (100 mg/25) mg heatstable tablets.

- Young children who weigh $>25 \mathrm{~kg}$ should use LPV/r (100 mg/25 mg) heat-stable tablets until they can be transitioned to DTG-containing regimens at 6 years of age.

- Weight bands rather than age should guide ARV dosing. However, DTG is only approved for children $>6$ years who weigh at least $15 \mathrm{~kg}$.

- At each clinic visit, children should be weighed and ART and other medications (such as TB drugs) doses should be adjusted based on change in body weight.

${ }^{1}$ LPV/r or ATV heat-stable tablets are made in a special embedded matrix formulation (a proprietary melt extrusion technology that stabilizes drug molecules that are normally heat-labile) and should not be cut, split, dissolved, chewed or crushed, since bioavailability is seriously reduced when not swallowed whole.

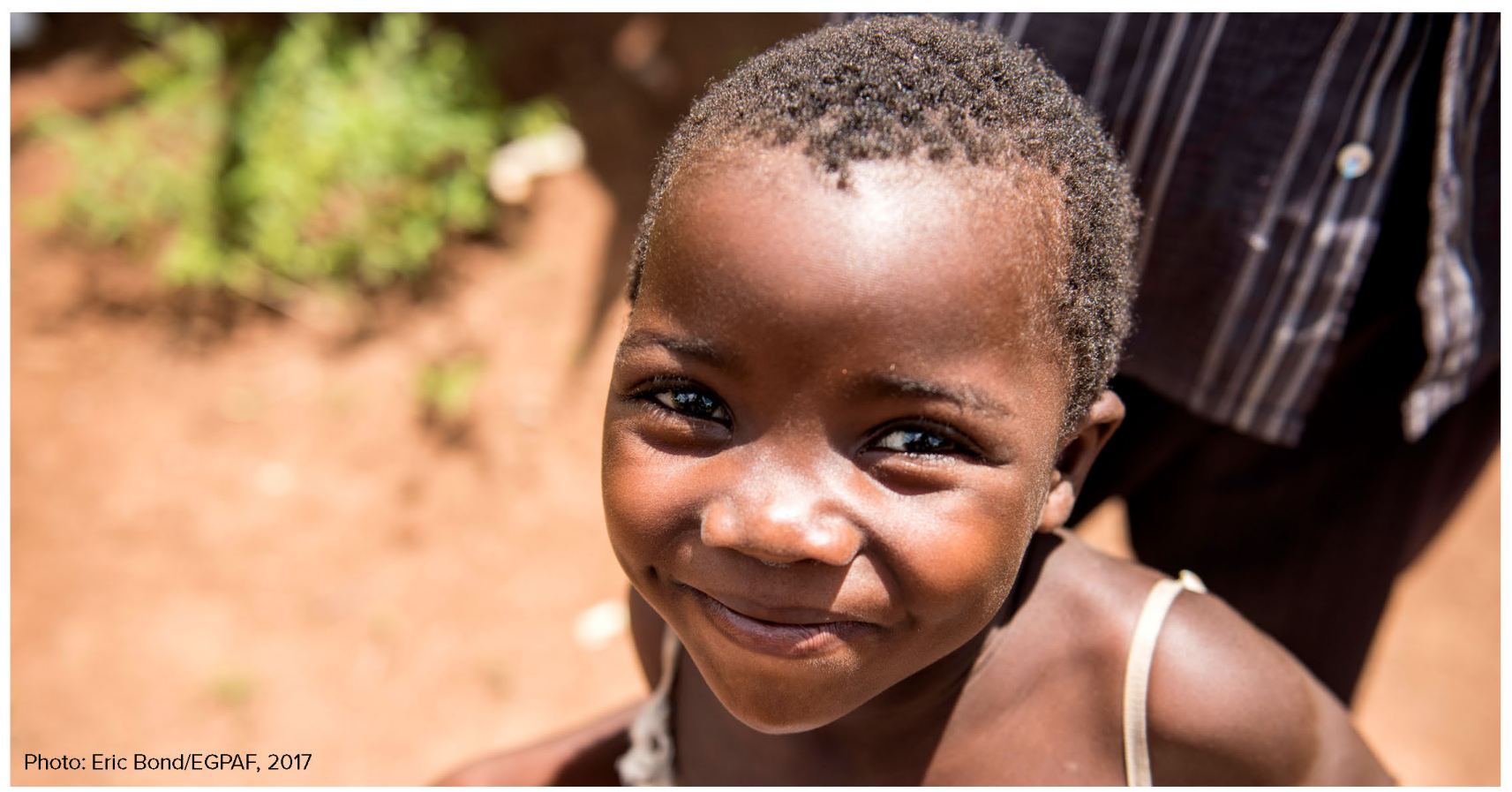

44 Piloting and evaluating family-centered care in Eswatini 


\section{APPENDIX 7}

\section{A MAP OF ESWATINI FAM-CARE STUDY SITES AND CATCHMENT AREA}

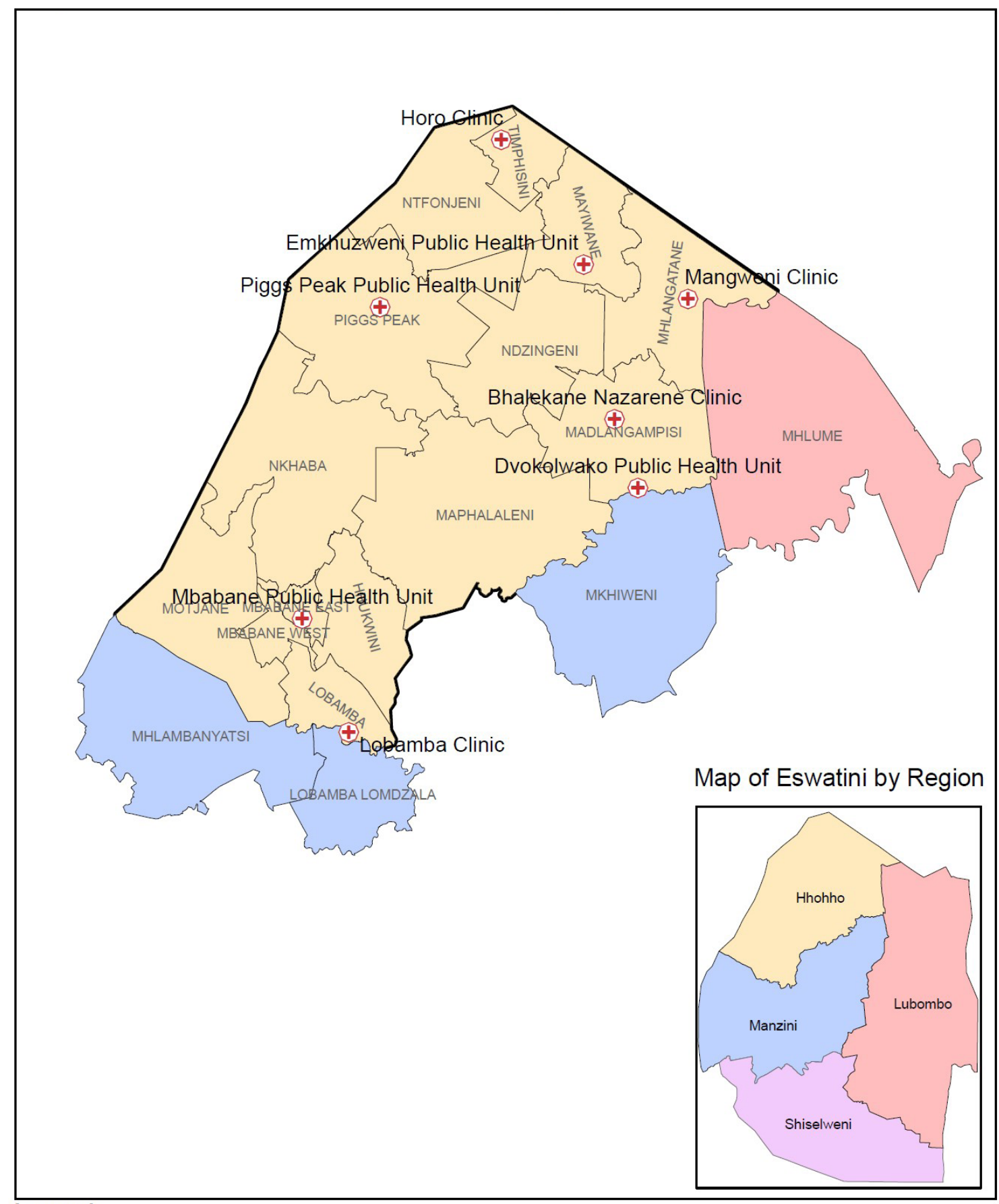

\section{Legend}

$\oplus$ FCCM Study Facilities

Region_ID
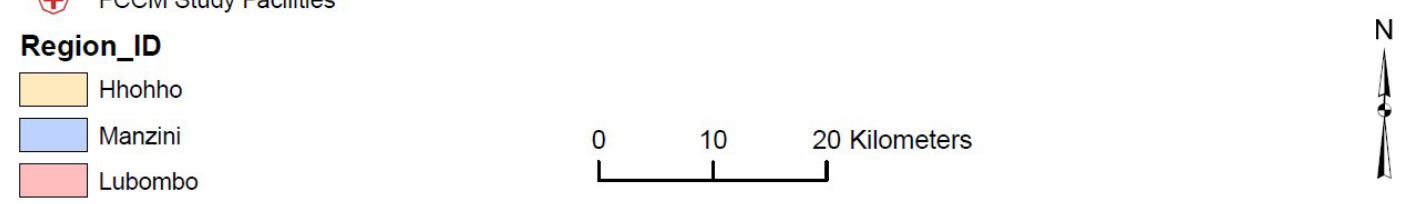
Project SOAR

Population Council 4301 Connecticut Ave, NW,

Suite 280

Washington, D.C. 20008 USA

Tel: +1 2022379400

Fax: +1 2022378410

Ideas. Evidence. Impact.

projsoar.org 